\title{
Deformation mechanisms and evolution of the microstructure of gouge in the Main Fault in Opalinus Clay in the Mont Terri rock laboratory $(\mathrm{CH})$
}

\author{
Ben Laurich $^{1, a}$, Janos L. Urai ${ }^{1}$, Christian Vollmer ${ }^{2}$, and Christophe Nussbaum ${ }^{3}$ \\ ${ }^{1}$ Institute for Structural Geology, Tectonics and Geomechanics, RWTH Aachen University, \\ Lochnerstrasse 4-20, 52056 Aachen, Germany \\ ${ }^{2}$ Institute for Mineralogy, University of Münster, Correnstraße 24, 48149 Münster, Germany \\ ${ }^{3}$ Swiss Geological Survey, Federal Office of Topography Swisstopo, Seftigenstrasse 264, 3084 Wabern, Switzerland \\ ${ }^{a}$ now at: Federal Institute for Geosciences and Natural Resources (BGR), Stilleweg 2, 30655 Hanover, Germany
}

Correspondence: Ben Laurich (ben.laurich@bgr.de)

Received: 7 June 2017 - Discussion started: 21 June 2017

Revised: 23 October 2017 - Accepted: 21 November 2017 - Published: 9 January 2018

\begin{abstract}
We studied gouge from an upper-crustal, lowoffset reverse fault in slightly overconsolidated claystone in the Mont Terri rock laboratory (Switzerland). The laboratory is designed to evaluate the suitability of the Opalinus Clay formation (OPA) to host a repository for radioactive waste.

The gouge occurs in thin bands and lenses in the fault zone; it is darker in color and less fissile than the surrounding rock. It shows a matrix-based, P-foliated microfabric bordered and truncated by micrometer-thin shear zones consisting of aligned clay grains, as shown with broad-ion-beam scanning electron microscopy (BIB-SEM) and optical microscopy. Selected area electron diffraction based on transmission electron microscopy (TEM) shows evidence for randomly oriented nanometer-sized clay particles in the gouge matrix, surrounding larger elongated phyllosilicates with a strict $\mathrm{P}$ foliation. For the first time for the OPA, we report the occurrence of amorphous $\mathrm{SiO}_{2}$ grains within the gouge. Gouge has lower SEM-visible porosity and almost no calcite grains compared to the undeformed OPA.

We present two hypotheses to explain the origin of gouge in the Main Fault: (i) "authigenic generation" consisting of fluid-mediated removal of calcite from the deforming OPA during shearing and (ii) "clay smear" consisting of mechanical smearing of calcite-poor (yet to be identified) source layers into the fault zone. Based on our data we prefer the first or a combination of both, but more work is needed to resolve this.
\end{abstract}

Microstructures indicate a range of deformation mechanisms including solution-precipitation processes and a gouge that is weaker than the OPA because of the lower fraction of hard grains. For gouge, we infer a more ratedependent frictional rheology than suggested from laboratory experiments on the undeformed OPA.

\section{Introduction}

Gouge is a fine-grained fault rock common in near-surface faults (Sibson, 1977; Vrolijk and van der Pluijm, 1999). It influences the mechanical and hydraulic properties of a fault, can act as a fluid barrier or conduit and typically forms a zone of mechanical weakness, which localizes further faulting. Hence, understanding the gouges' physical rock properties is essential in hydrocarbon exploration and production, hydrogeology, earthquake research and nuclear waste disposal.

As a follow-up to our publications on micrometer-thin shear zones and on scaly clay from the Main Fault in the Mont Terri underground research laboratory (MT URL) (Laurich et al., 2014, 2017; Laurich, 2015), in this paper we address the mineralogy and microstructure of gouge from the Main Fault to infer physical rock properties, underlying deformation mechanisms and the evolution of the gouge. In this work, we built upon many gouge-related microstructural 

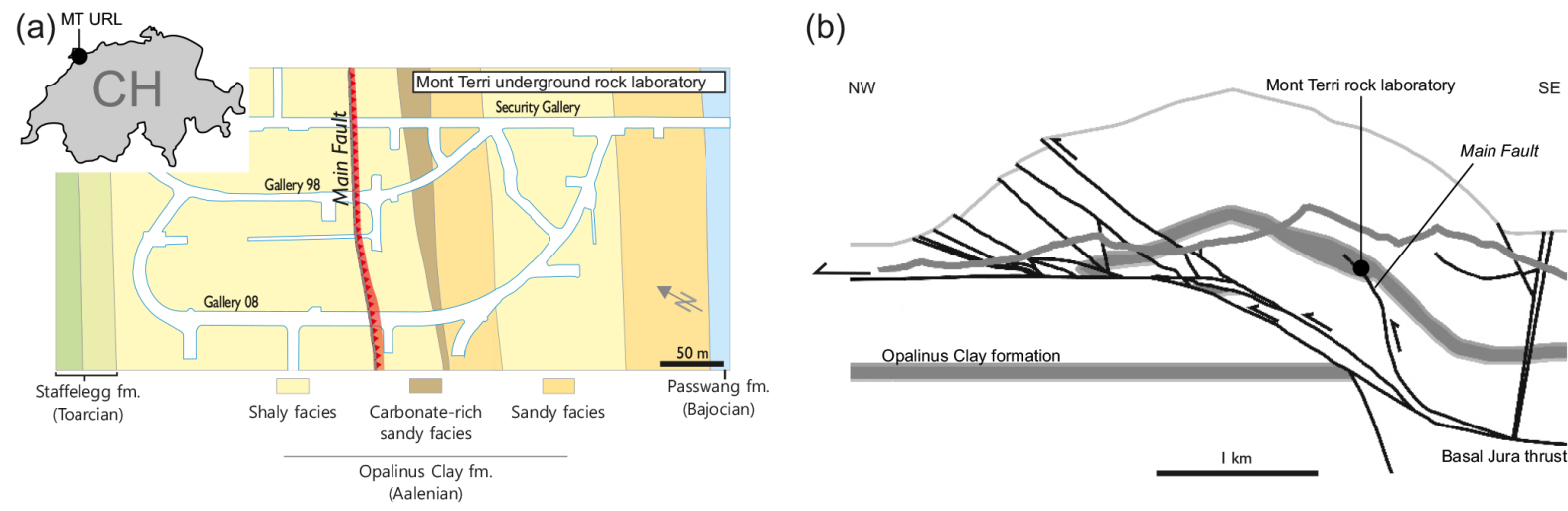

(c)
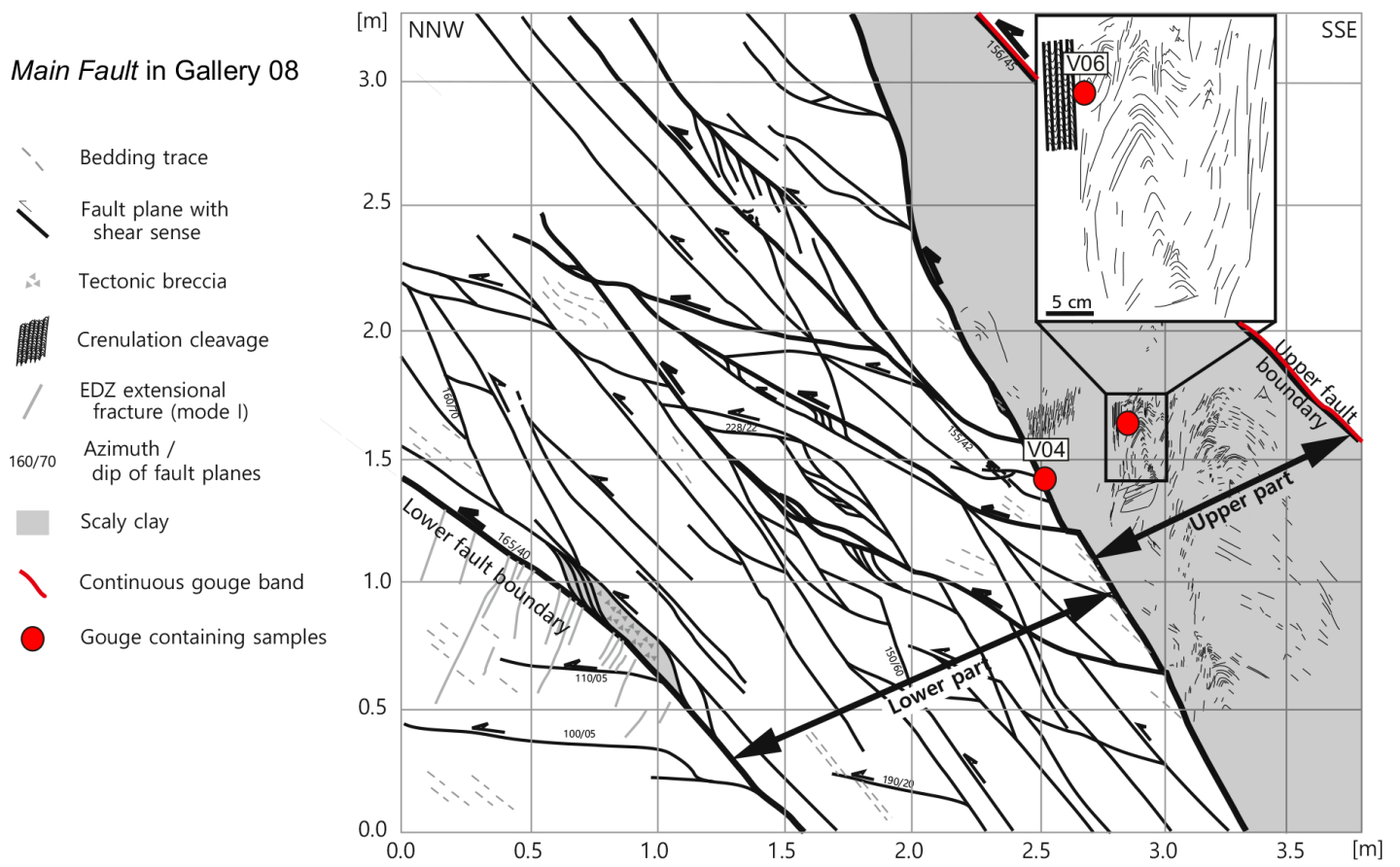

Figure 1. (a) Location map of the Main Fault in the Mont Terri research laboratory, (b) cross section modified from Freivogel and Huggenberger (2003) and (c) outcrop sketch of the Main Fault in gallery 08 modified from Nussbaum et al. (2011).

studies. Although we cannot cite all of these, we include a categorized literature overview in the Supplement (without a claim for completeness).

\section{Geology and sample origin}

As its main objective, the MT URL evaluates the longterm safety of radioactive waste disposal. A detailed description on the local geological setting can be found in Nussbaum et al. (2011, 2017), Jaeggi et al. (2017), Bossart and Thury (2008), and Becker (2000). The Main Fault is a low offset $(<80 \mathrm{~m})$ reverse fault; it forms a $0.8-3 \mathrm{~m}$ wide fault zone in the shaly facies of the Opalinus Clay formation (OPA) at the MT URL. The fault zone is heterogeneous: it consists of gouge, scaly aggregates (sensu Vannucchi et al., 2003), S-C bands, mesoscale folds, microfolds, numer- ous micron-thick shear zones, which form shiny slickenside surfaces when broken, and blocks of the undeformed OPA (Fig. 1).

The environmental and lithological controls at the onset of faulting in the late Miocene (Nussbaum et al., 2011, 2017) have been inferred as follows: $55^{\circ} \mathrm{C}$ temperature; $1000 \mathrm{~m}$ overburden; subhorizontal, NNW-SSE-oriented $\sigma_{1}$; progressive faulting in a shear-fault bend fold (the MT anticline); calcite and celestite veins indicating paleo-fluid flux during faulting; slightly over-consolidated protolith (maximum burial $1350 \mathrm{~m}, 85^{\circ} \mathrm{C}$ ) with $8-24 \%$ porosity (Mazurek et al., 2006; Nussbaum and Bossart, 2008; Houben et al., 2013; de Haller et al., 2014; Laurich et al., 2014). The present permeability of the OPA is very low with no significant hydrological contrast between wall rock and the Main Fault 
$\left(2 \times 10^{-13} \mathrm{~m} \mathrm{~s}^{-1}\right.$, Nussbaum and Bossart, 2008). Profiles of a range of pore fluid geochemical tracers are not perturbed near or within the Main Fault (Mazurek et al., 2011). The OPA has a strongly anisotropic unconfined compressive strength between 6 and $28 \mathrm{MPa}$ (Bock and Blümling, 2001; Amann et al., 2011).

Gouge is present in all outcrops of the Main Fault known to the authors. It occurs as a thin (up to $2 \mathrm{~cm}$ ) but continuous dark band at the upper fault zone boundary in Fig. 1 but also occurs inside the Main Fault zone. Gouge can be recognized by is its dark, matte appearance compared to the undeformed OPA. Gouge has sharp boundaries and is, at least to one side, always bordered by scaly clay (Fig. 2).

The aim of this paper is to characterize gouge microstructure using optical and electron microscopy to evaluate the evolution of gouge during movement of the Main Fault, and finally to discuss the mechanical and fluid flow properties of the Main Fault during its geological evolution.

\section{Methods}

The samples were retrieved from drill cores BIC-A1 and BPS-12 and from all Main Fault outcrops in the MT URL. Drill core samples have the well name as a prefix; outcrop samples are named with the prefix "V" or "A". The samples were transported in vacuum-sealed bags and resin-stabilized in the lab. Due to the fragile nature of the specimen, sampling and sample preparation were conducted with great care and without the use of water (except when on purpose and explicitly stated).

\subsection{Microstructure}

The resin-stabilized samples were sectioned approximately parallel to the outcrop wall, i.e., parallel to the inferred main principle displacement and perpendicular to bedding. The cut samples were further treated in three different ways: (1) water immersion, (2) ultrathin sectioning and (3) subsampling for broad-ion-beam (BIB) polishing. Some polished samples were decorated by spraying a thin water film on the polished sample surface using an aerosol can. Immediate drying of the water results in a fine decoration of the foliation by differential swelling of the clay matrix. Ultrathin $(<10 \mu \mathrm{m})$ sections for optical microscopy were produced by Geoprep (Basel). Subsamples were cut dry with a thin $(0.3 \mathrm{~mm})$ circular diamond saw, manually ground using abrasive paper down to 2400 grit and subsequently polished using a BIB. Two argon BIB devices were used: (1) a JEOL SM-09010 operating at $6 \mathrm{kV}$ and $150-200 \mu \mathrm{A}$ for $7.5-10 \mathrm{~h}$, producing $2 \mathrm{~mm}^{2}$ sections, and (2) a Leica TIC $3 \mathrm{X}$ operating at $5-7.5 \mathrm{kV}$ and $2-2.8 \mathrm{~mA}$ for $2 \mathrm{~h}$, with the angle varying between 4.5 and $10.5^{\circ}$, polishing subsample surfaces of up to $1 \mathrm{~cm}^{2}$.

The samples were imaged using an optical microscope as well as a scanning electron microscope (SEM): a Zeiss

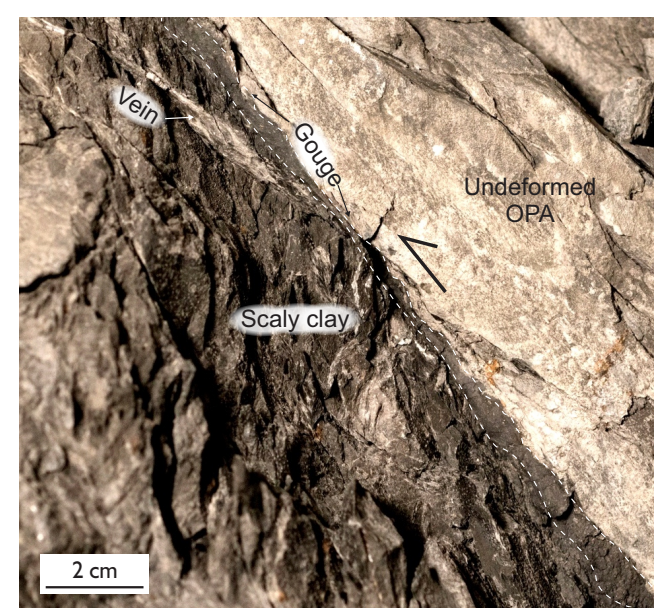

Figure 2. Outcrop picture of the continuous gouge band at the upper fault zone boundary in gallery 98 (view to ENE).

Supra 55 field emission SEM operating at $3-30 \mathrm{kV}$ in secondary electron (SE) and in backscattered electron mode and also using energy-dispersive X-ray spectroscopy (EDX). Water-decorated samples were imaged in oblique incident light with optical microscopy. Ultrathin sections were imaged in transmitted light microscopy (xpol, full wave plate) and in the SEM. A total of 11124 grains were manually segmented from two BIB-SEM backscattered electron micrograph mosaics. Both micrographs show similar contrast with the same high level of detail. Segmentation and statistics were done using ArcGIS 10.3, ImageJ 1.51a, RStudio 0.99 and MS Excel 2013. BIB-SEM and corresponding statistical procedures are described in detail in other microstructural clay studies from the Aachen GED Group (Houben, 2013; Hemes, 2015; Klaver, 2015; Laurich, 2015; Desbois et al., 2016). Shape factors are defined as

axial ratio $=\frac{\text { width }}{\text { length }}$,
circularity $=\frac{4 \pi \times \text { area }}{\text { perimeter }^{2}}$.

Grain orientations are presented in rose diagrams, weighted by the grains' axial ratio, i.e., a grains' contribution to an orientation bin increases with increasing elongation. Grains that are as wide as they are long (axial ratio $=1$ ) do not contribute at all:

$N=\sum_{1}^{k} m_{i} \times\left(1-\right.$ axial $\left._{\text {ratio }_{i}}\right)$,

where $N$ is the basic population, $k$ the number of bins ( $k=$ 18 bins a $10^{\circ}$ ) and $m_{i}$ a function that counts the number of observations that fall into each bin. The raw data as well as their processing are provided as a Supplement to this article.

Transmission electron microscopy (TEM) techniques were applied on focused-ion-beam-prepared lamellae of 
$10 \times 5 \times 0.15 \mu \mathrm{m}^{3}$ (length, width, thickness). We used an FEI Strata 205 focused ion beam $(30 \mathrm{kV}, 20 \mathrm{nA}-100 \mathrm{pA}$, tungsten coating; Central Facility for Electron Microscopy, University of Aachen) and a Zeiss Libra 200FE (200 kV Schottky field emitter, Köhler illumination system, incolumn Omega energy filter; Institute for Mineralogy, University of Münster). High-angle annular dark field (HAADF) scanning TEM (STEM) and bright field (BF) images were collected, giving information on average atomic number and mainly diffraction contrast, i.e., crystallinity of illuminated areas, respectively. We performed EDX measurements to specify major element characteristics using a $\mathrm{Si}(\mathrm{Li})$ detector. To minimize sample damage, only short dwell times were applied. Selected area electron diffraction patterns were recorded to specify crystallographic parameters of regions of interest within the focused-ion-beam lamellae.

\subsection{Bulk analyses}

In addition to electron-microscopy-based EDX, we used Xray diffraction to determine mineralogical phases. This analysis was performed on two different devices: a Bruker D5000 and a Huber MC9300. Quantification was performed by Rietveld refinement, using the software TOPAS and BGMN, for patterns recorded with the Bruker D5000 and the Huber MC9300, respectively. We followed procedures as published in Kahle et al. (2002) and Ufer et al. (2008). Diffractograms were recorded with $2 \Theta$ ranging from $2^{\circ}$ to $92^{\circ}$, with long counting times. EDX was accomplished with silicon drift detectors on both electron microscopy devices: the SEM and TEM instrument.

Vitrinite reflectance and total organic carbon of gouge and surrounding wall rock were determined at the Institute of Geology and Geochemistry of Petroleum and Coal, RWTHAachen. Vitrinite was measured using a Zeiss Axio Imager microscope. The sample preparation was carried out perpendicular to bedding foliation by dry polishing with carbide abrasive papers down to 4000 grit. We followed the procedure in Littke et al. (2012) and Bou Daher et al. (2014). Organic carbon measurements were performed with a liquiTOC II analyzer. The temperature ramp was $300{ }^{\circ} \mathrm{C} \mathrm{min}^{-1}$ up to $550^{\circ} \mathrm{C}$; released $\mathrm{CO}_{2}$ was detected with a nondispersive infrared detector.

\section{Results}

\subsection{Microstructure}

Gouge displays a systematic, geometric microstructure. In the outcrop, it stands out due to its matte black color in surfaces broken perpendicular to the foliation and wavy, smooth, shiny slickenside shear surfaces (Figs. 2, 3). Gouge can be disintegrated into fine powder between two fingers and becomes sticky when wet. It displays sharp boundaries to the surrounding wall rock, often in a distinct straight line (e.g.,
Fig. 4d and e), but sometimes highly irregular (Fig. 5). The wall rock is either undeformed protolith or scaly clay and is often enriched in micro-calcite veins that are frequently strained and in Riedel orientation to the main shortening axis of the Main Fault (Fig. 4a, b, c and e, wall rock veins in Fig. 5c). There are no veins inside the gouge. Figure 17 displays a generic sketch of all microstructural elements in gouge.

\subsubsection{Gouge-internal foliation and gouge-internal shear bands}

The gouge-internal foliation can be decorated using the water immersion technique (Figs. 4-7). It shows a distinctive, well organized $\mathrm{P}$ foliation (orientation nomenclature sensu Logan et al., 1979) with a high fabric intensity (sensu Yan, 2001; Haines et al., 2009). Correspondingly, ultrathin sections of gouge display a uniform extinction pattern along the $\mathrm{P}$ foliation under crossed polars (not shown here; refer to Laurich et al., 2014).

By slight foliation and brightness variations, two types of gouge can be differentiated: (1) less dark gouge with a high angle $\mathrm{P}$ foliation to shear direction and (2) dark gouge with a low angle or almost parallel $\mathrm{P}$ foliation to shear direction (Figs. 4, 5, 6). Using SEM-EDX, the brightness differences between both gouge types can be attributed to Ca content, which is lowest in type 2, followed by type 1 , and highest in the wall rock and in wall rock clasts (Figs. $4 \mathrm{~b}$ and c, 6). The border of both gouge types is usually very sharp along the $\mathrm{Y}$ orientation (Figs. 4e, 6b). Gouge type 2 is occasionally bordered by type 1 on both sides (Fig. 6), but in general has one border to brighter wall rock (Fig. 4d).

The gouge-internal foliation is reflected in a slight sigmoidal "drag-in" shape at the gouge zone boundaries (Figs. 4d and e, 7), where micrometer-wide bands of shearparallel foliation resemble Y shears. Such bands of parallel foliation can be spotted inside the gouge, too. They occur mostly in $\mathrm{Y}$ and $\mathrm{R}$ orientations and are less abundant in $\mathrm{R}^{\prime}$ orientation (exemplarily outlined in Fig. 6). Framed between these bands, the $\mathrm{P}$ foliation in gouge type 1 displays a sigmoidal style, comprising an S-C fabric (Fig. 4a and b, left in type 1 gouge, and Fig. 6). The foliation pattern of gouge type 1 continues into the scaly wall rock (right part in Fig. 4a, b). The gouge-internal bands can also be seen in large-area BIB polished samples imaged by reflected light microscopy in Fig. 8c and d. The figure displays a wavy net of approximately $30 \mu \mathrm{m}$ wide bands that are slightly darker than the gouge matrix. In the SEM, the dark bands were identified as semicontinuous, 15 to $50 \mu \mathrm{m}$ wide shear bands, which are exposed by a distinct change in particle orientation (Fig. 9-12). The borders of the gouge-internal shear bands can be very sharp (Figs. 9a and b, 10d) or diffuse, such as the lower shear band boundary in Fig. 11b. To define such a diffuse boundary is subjective and other interpreters might trace a number of branches of the shear band, which often nucleate and die out 

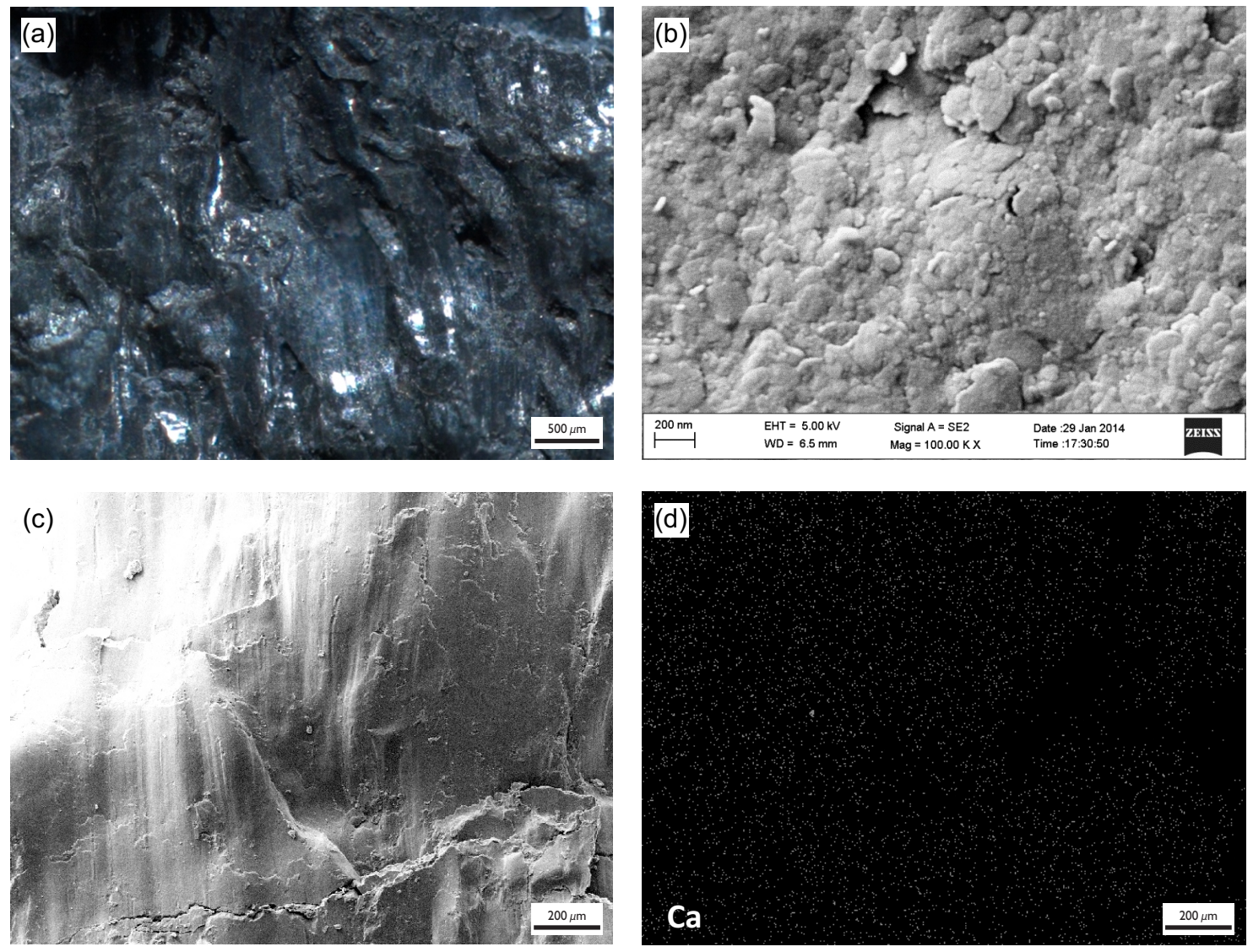

Figure 3. (a) Top view of broken shear zone surfaces (slickenside surface) in gouge (sample BPS12-4-S1). (a) Reflected light photograph and (b, c) SEM (SE) micrographs displaying nanometer-sized clay particles on a smoothly polished slickenside surface. (d) SEM-EDX Ca distribution map of panel (c). Contrary to shear zones in the undeformed OPA, there is no Ca present, not even at slickenside risers.

next to larger grains. The level of detail here is in the order of the grain size. In a similarly subjective fashion, we traced a number of micrometer-wide shear zones (Fig. 10b) that run through the shear bands and that define the bands' sharp borders as Y shears (Fig. 10d), consistent with findings by Logan et al. (1992).

Contrary to the undeformed OPA, the gouge microstructure contains no fossils and has a much higher fabric intensity and drastically less calcite grains. Many smaller open fractures are present, which we confidently interpret as artifacts from desiccation and/or unloading (see Dehandschutter et al., 2005; Houben, 2013). Figure 11 provides a micrograph comparison of gouge and the undeformed OPA (shaly facies).

\subsubsection{Quantitative grain analysis}

The following compares grain size distributions (GSDs), orientations and shapes of the undeformed OPA (sample V08) and gouge (sample V15-4). Both BIB-polished samples derive from the Main Fault: V08 from an undeformed part in gallery 08 (outcrop to the SSW), V15-4 from the upper fault zone boundary in gallery 98 (outcrop to the SSW). The area examined in sample V08 is $7395 \mu \mathrm{m}^{2}$, with 6410 manually segmented grains that fall completely inside the area. The area of sample V15-4 is $3600 \mu \mathrm{m}^{2}$, with 5000 grains that fall completely inside the area (Fig. 11).

Figure 12a displays the density GSDs of both samples following the power-law equation:

$\frac{N_{i}}{\left(\mathrm{bw}_{i} \times \mathrm{At}\right)}=C \times \mathrm{bc}_{i}^{-D}$,

where $N_{i}$ is the number of grains within bin $i$, with an exponential increasing bin width $\mathrm{bw}_{i}$. The frequencies are normalized by the examined area At for sample comparability. The $x$ axis in Fig. 12a displays the bin centers $\left(\mathrm{bc}_{i}\right)$, and $C$ is a constant of proportionality. Both samples show an almost identical power-law exponent $D$, which has been derived using the least squares method using the logarithm of the data. The validity of both power-law models within the chosen ranges (boxes in Fig. 12a) is supported by constant values in local slope (see Bonnet et al., 2001, and references therein), shown as thin grey lines in Fig. 12a. Therein, the local slope $\left(D_{1}\right)$ is calculated by 

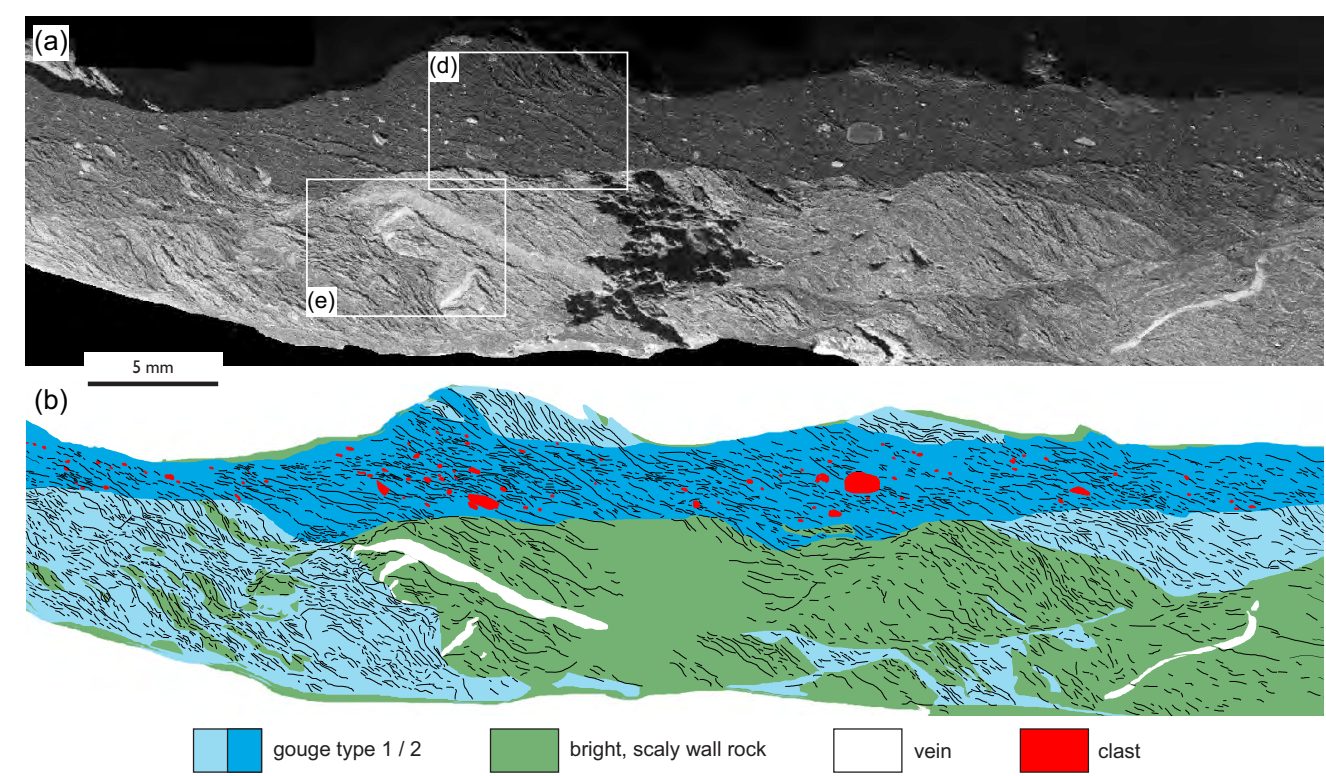

(c)
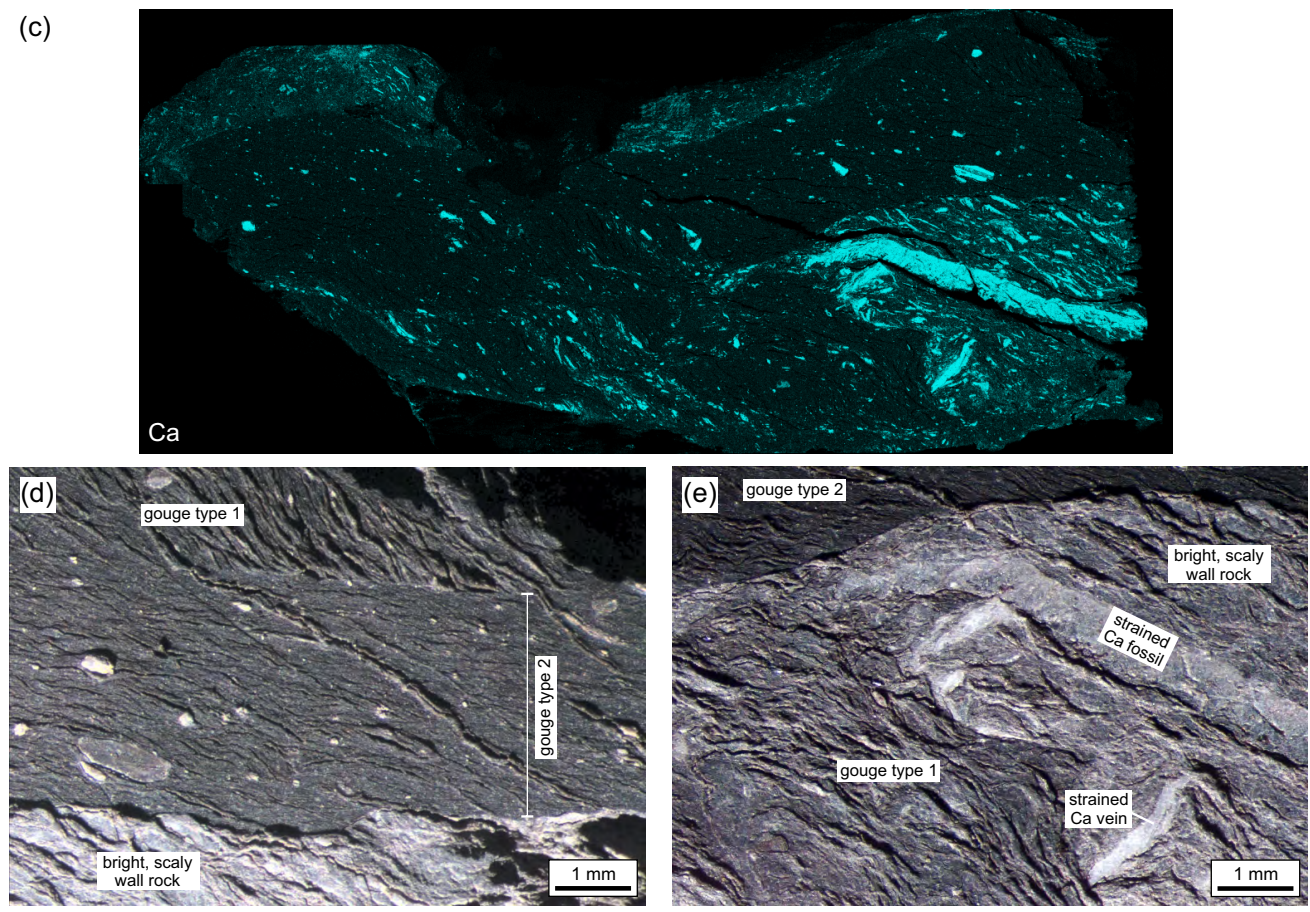

Figure 4. Illustration of (i) the sharp gouge (dark) to wall rock (bright scaly clay) contact, (ii) the distinct boundary between types 1 and 2 gouge, (iii) the gouge-internal $\mathrm{P}$ foliation and (iv) gouge-internal clasts, and (v) surrounding calcite veins. (a) Shaded light photograph of water-immersed hand specimen V15 with (b) sketch and (c) SEM-EDX Ca distribution map of the sample. Note that gouge is drastically reduced in Ca compared to scaly wall rock. Panels (d) and (e) are insets of panel (a). See text for details.

$D_{1}=\frac{\log \left(\frac{N n_{i}}{C}\right)}{\log \left(\mathrm{bc}_{i}\right)}$.

Deviations of recorded frequencies from the power law (diamonds in Fig. 12a) can be attributed to resolution limitations (truncation), i.e., the smaller the grains, the more often they are missed in the segmentation (see Bonnet et al., 2001).

The similarity in the power-law exponents (1.98 and 1.97 for V15-4 and V08, respectively) suggests that both samples have a similar GSD. However, this cannot hold true for values below the regression range: only $30.7 \%$ of sample V154 was segmented (either as grains or pores), the remain- 

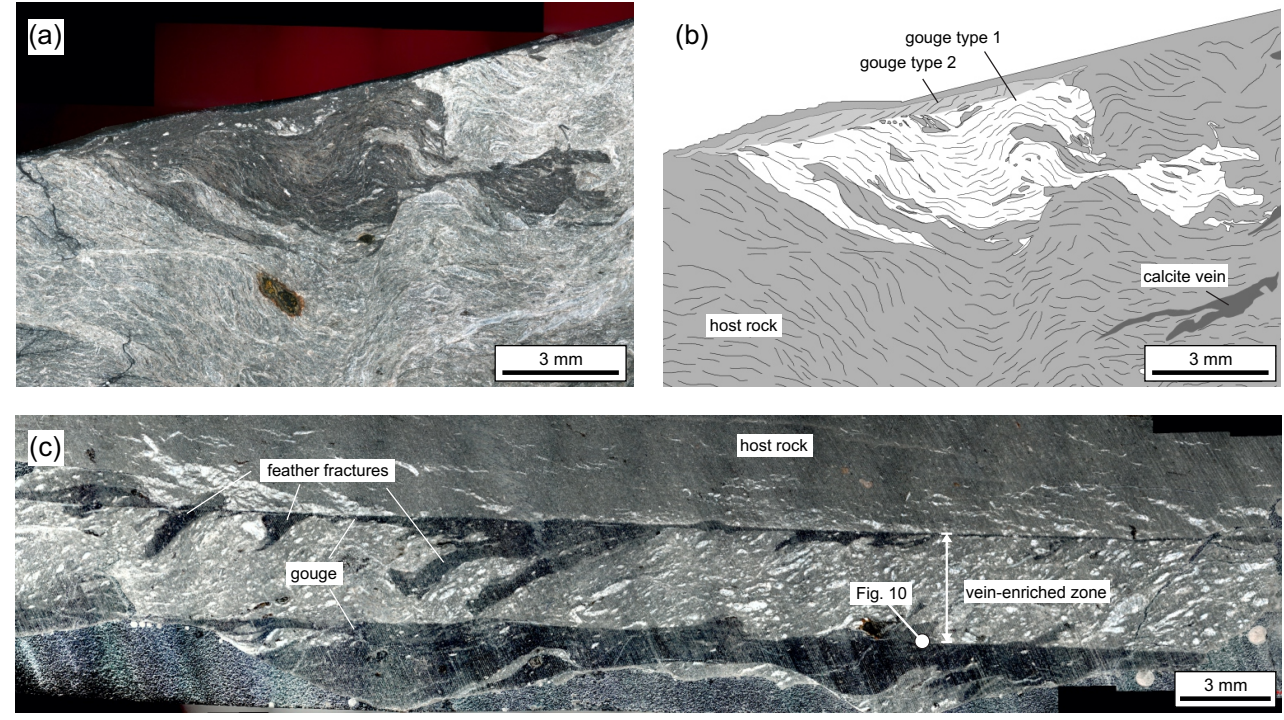

Figure 5. Injection-like textures of gouge into scaly wall rock. (a) Reflected light micrograph and (b) sketch of sample V06. (c) Reflected light micrograph of sample A1. Note that the feather fractures are synthetic; the shape of wall rock clasts in panel (a) follow the gouge foliation. A band of gouge type 2 is visible at the upper border of the sample in panel (a). See text for details.

ing (from here on termed matrix) not being SEM-resolvable. Conversely, $47.1 \%$ was segmented in sample V08, although both BSE micrographs were recorded with equal magnifications and brightness contrasts and were both manually segmented with the same good level of detail (we recommend looking at a close-up of Fig. 11). The effect of this difference in total segmented area is illustrated in the cumulative GSDs (Fig. 12b): a continuous trend in the cumulative GSD of sample V15-4 beyond the range depicted in Fig. 12a down to $1 \mathrm{~nm}^{2}$ grain size sums up to a total grain area of $70 \%$, leaving $30 \%$ unexplained. We therefore hypothesize a GSD for gouge with a very high contribution of smallest grains below the resolution limit $\left(\sim 10000 \mathrm{~nm}^{2}\right)$. The undeformed sample V08 shows that $100 \%$ would be realized by following the cumulative GSD trend down to $16 \mathrm{~nm}^{2}$ grain size. Note that in Fig. 12b the cumulative GSDs do not add up to $100 \%$. The lacking part (6.67 and $1.62 \%$, for samples V08 and V15-4, respectively) is the area segmented as pores, open fractures and those grains that do not fall completely inside the examined area and are thus excluded from the GSD analysis.

The rose diagrams in Fig. 12c show a clear grain orientation difference inside and outside the shear band. The undeformed OPA also shows a small scatter in grain orientation, which reflects the bedding foliation (Fig. 12c). Note that entries in the rose histogram are weighted by their axial ratio in order to enhance the main fabric orientation (Eqs. 1 and $3)$. Shape factor distributions are shown in Fig. 12d. The proportionality of axial ratio and circularity (Eq. 2), wherein the axial ratio is larger than the circularity, is indicative of angular shapes with little surface roughness, such as the box- shaped, elongated phyllosilicates. Grains within the undeformed OPA display small values in circularity more often than grains in gouge, while the axial ratio is similar in both samples. This difference in circularity can be attributed to a higher surface roughness for grains in the undeformed OPA.

Analysis of porosity in the gouge is somewhat subjective because of the presence of open microfractures in the BIBpolished sample, which we interpreted as artifacts formed after excavation of the MT URL gallery. Such fractures are much less common in the undeformed OPA (Houben et al., 2013), perhaps because gouge has a much stronger foliation. Still, the SEM-visible porosity in gouge including the fractures (Figs. 11, 13) is much smaller than in the undeformed OPA ( 0.84 and $2.4 \%$, respectively). Gouge material in between larger fractures shows clearly less visible porosity than the undeformed OPA at the same resolution (Fig. 13). Pores abundant in calcite fossils and in the less intensely foliated clay matrix of the undeformed OPA are completely absent in the gouge micrographs (Fig. 13e vs. b). The undeformed OPA has $18 \%$ porosity as the best estimate (Nussbaum and Bossart, 2008; Houben et al., 2014). In recent work, high porosities for the OPA gouge ( $>20 \%$ ) were found using mercury injection porosimetry and He pycnometry in Orellana et al. (2016), dominated by pores $<14 \mathrm{~nm}$. However, it is unclear to what extent the applied methods are comparable to the BIB-SEM findings: are artificial openings excluded and are poro-elastic effects considered (see Sigal, 2009; Klaver et al., 2012; Hemes et al., 2013; Houben et al., 2014)? 



Figure 6. P-foliation patterns, grain and wall rock clasts as well as micrometer-thin shear zones in gouge. (a) Water-immersed hand specimen V17 photographed in shaded light. (b) Inset of panel (a) and (c) sketch of panel (a). Note the S-C resembling sigmoidal P foliation and the strict boundary separating type 1 and type 2 gouge. See text for details.

\subsubsection{Wall rock clasts and survivor grains}

Gouge type 1 frequently incorporates bright wall rock clasts, which are oriented parallel to the $\mathrm{P}$ foliation or in $\mathrm{Y}$ orientation (Figs. 4-8). Often they match shape and orientation of the adjacent wall rock boundary and we interpret them as detached wall rock material (Figs. 5, 7). Nevertheless, from the pictures it remains unclear whether they are teared-off from the wall by gouge intrusion or if their neighboring material was reworked into gouge or both. Wall rock clasts are frequently sheared along gouge-internal Y and R shears. Arrays of wall rock clasts typically resemble the appearance of one half of a feather: their sigmoidal clasts are aligned parallel to the $\mathrm{P}$ foliation like several feather spikes that are attached to a feather shaft, with the feather shaft being the $\mathrm{Y}$ shear (Fig. 7a, c).

Contrary to wall rock clasts, mineral grain clasts (or "survivor grains"; Cladouhos, 1999b) are rare in gouge type 1 and frequent in gouge type 2 (Figs. 4, 6). They are large, Pfoliation-parallel particles of calcite or feldspar, which are often fractured and show spalled fragments. Typically, these fragments are located in pressure shadows of the grains (see larger grain in the very left of Fig. 6a).

\subsubsection{Gouge matrix}

The BIB-SEM (BSE) shows grains down to about $100 \mathrm{~nm}$ width (Fig. 9). However, these grains are clasts to a matrixbased fabric of even smaller particles, which are not resolvable, even using high-resolution TEM, because the focusedion-beam lamella thickness is clearly larger than individual particle sizes (Fig. 14b). TEM-EDX and the selected area electron diffraction pattern indicate that the matrix comprises ultrafinely grained $(<10 \mathrm{~nm})$, polycrystalline clay particles in various orientations (Fig. 14c; see Viti, 2011). The presence of such small particles is in agreement with the GSD above, 


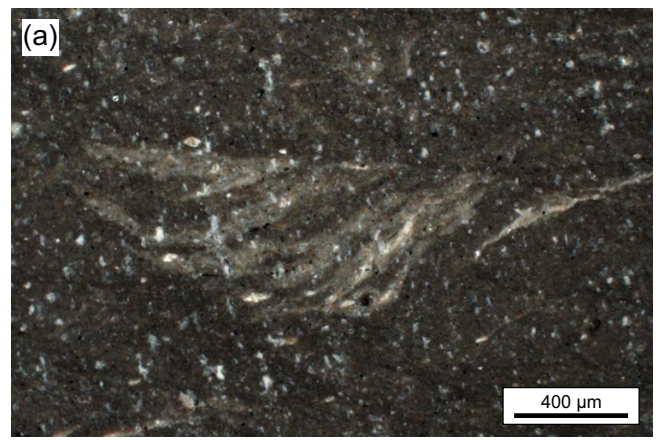

(b)
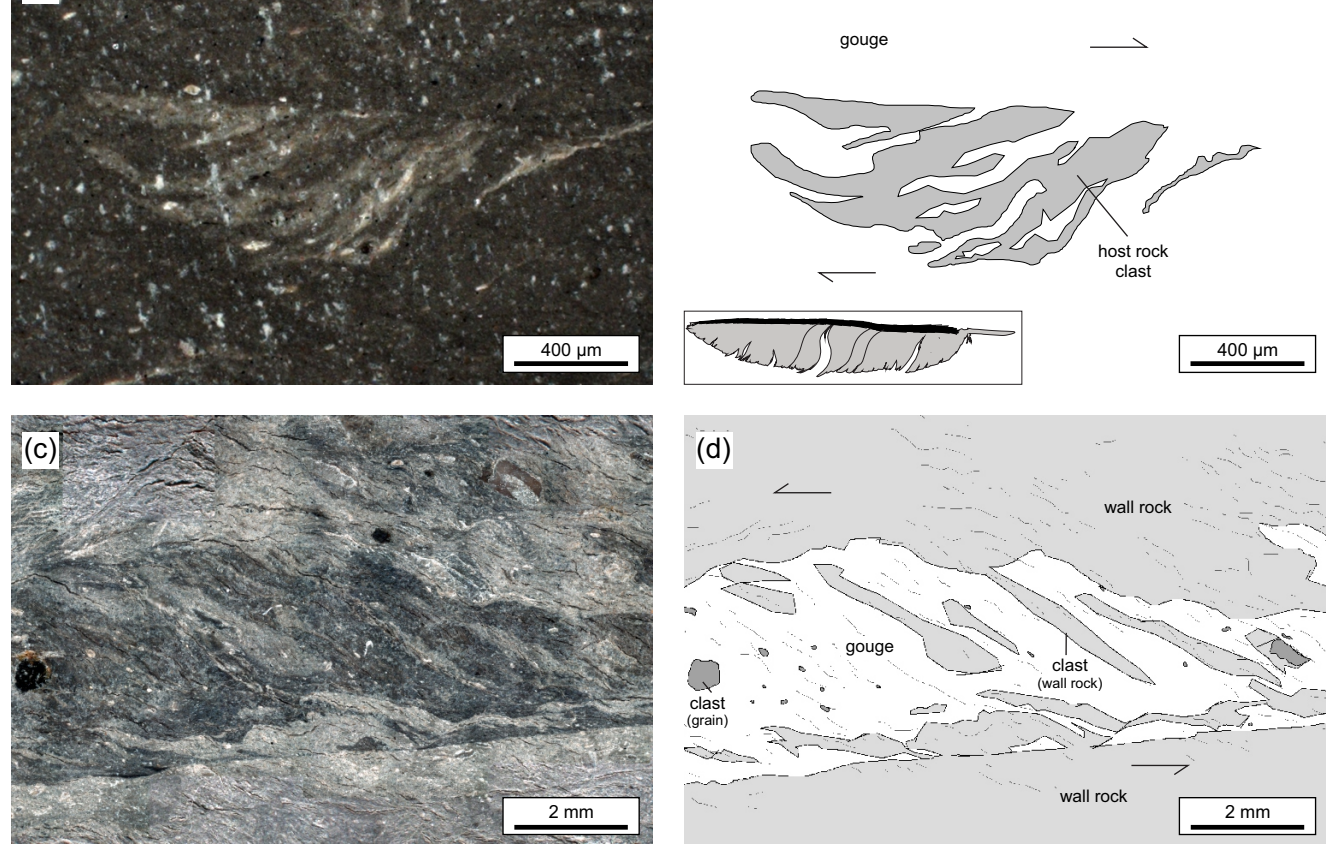

Figure 7. Host rock clasts in gouge type 1. (a) Reflected light micrograph and (b) sketches of sample A9c-1 polished using a large-area BIB. (c) Shaded light photograph of water-immersed sample V04 showing foliation. Note the sigmoidal S-C like pattern of the clasts, which suggests a progressive rework of the host rock into gouge. See text for details.
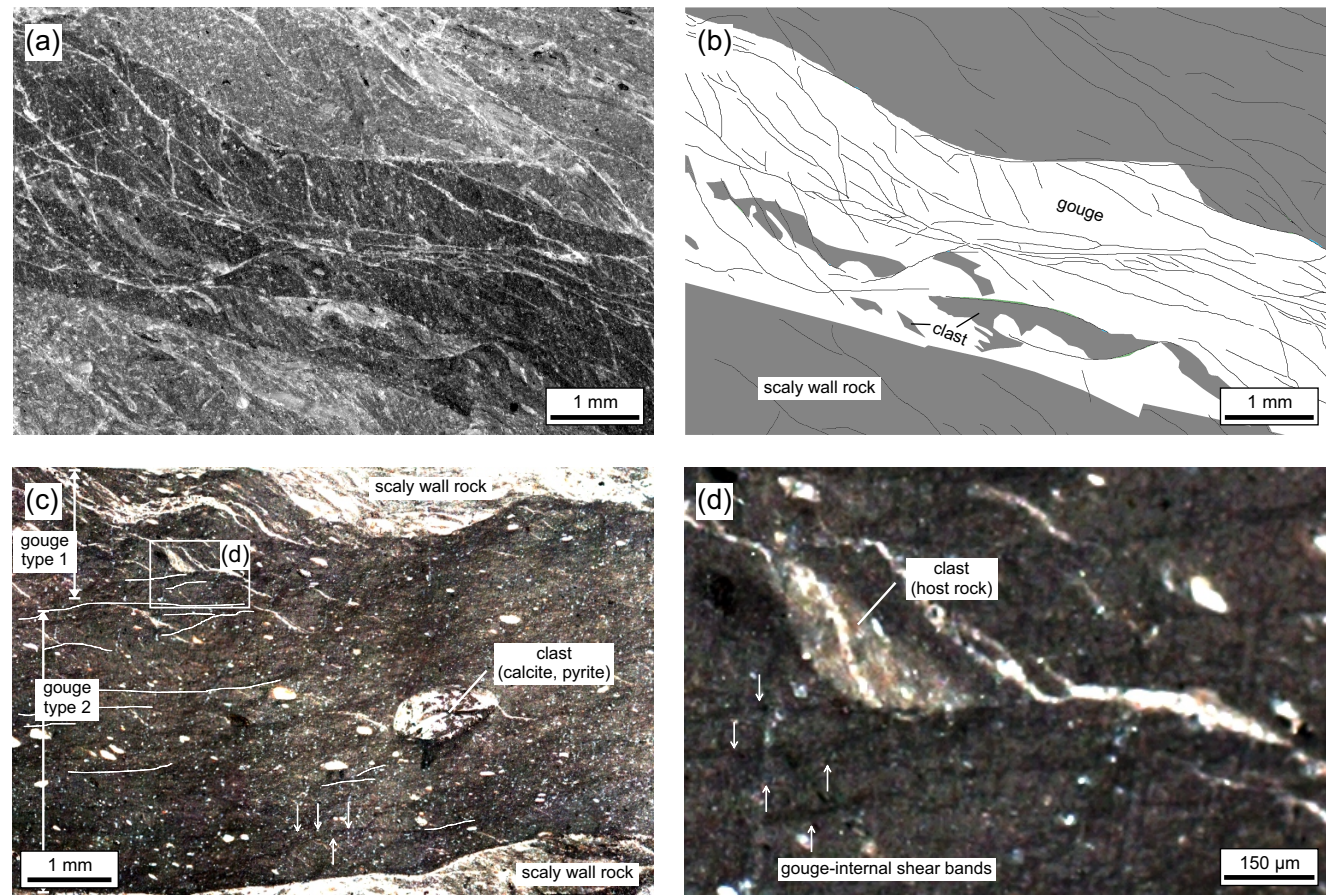

Figure 8. Series of shear zones within gouge and surrounding wall rock (scaly clay) as well as host rock clasts. (a, c, d) Reflected light micrographs, (b) sketch of panel (a) and (d) inset of panel (c). Dashed lines and arrows mark the wavy net of dark shear bands, which are wider than micrometer-thin shear zones (see Fig. 11). (a, b) Sample A3-1 polished with 800 grid grinding paper and (c, d) sample V15-T2 polished using a large-area BIB. The images are contrast enhanced to make the black bands stand out. Best viewed in a high-quality color print or as a magnified pdf. See text for details. 

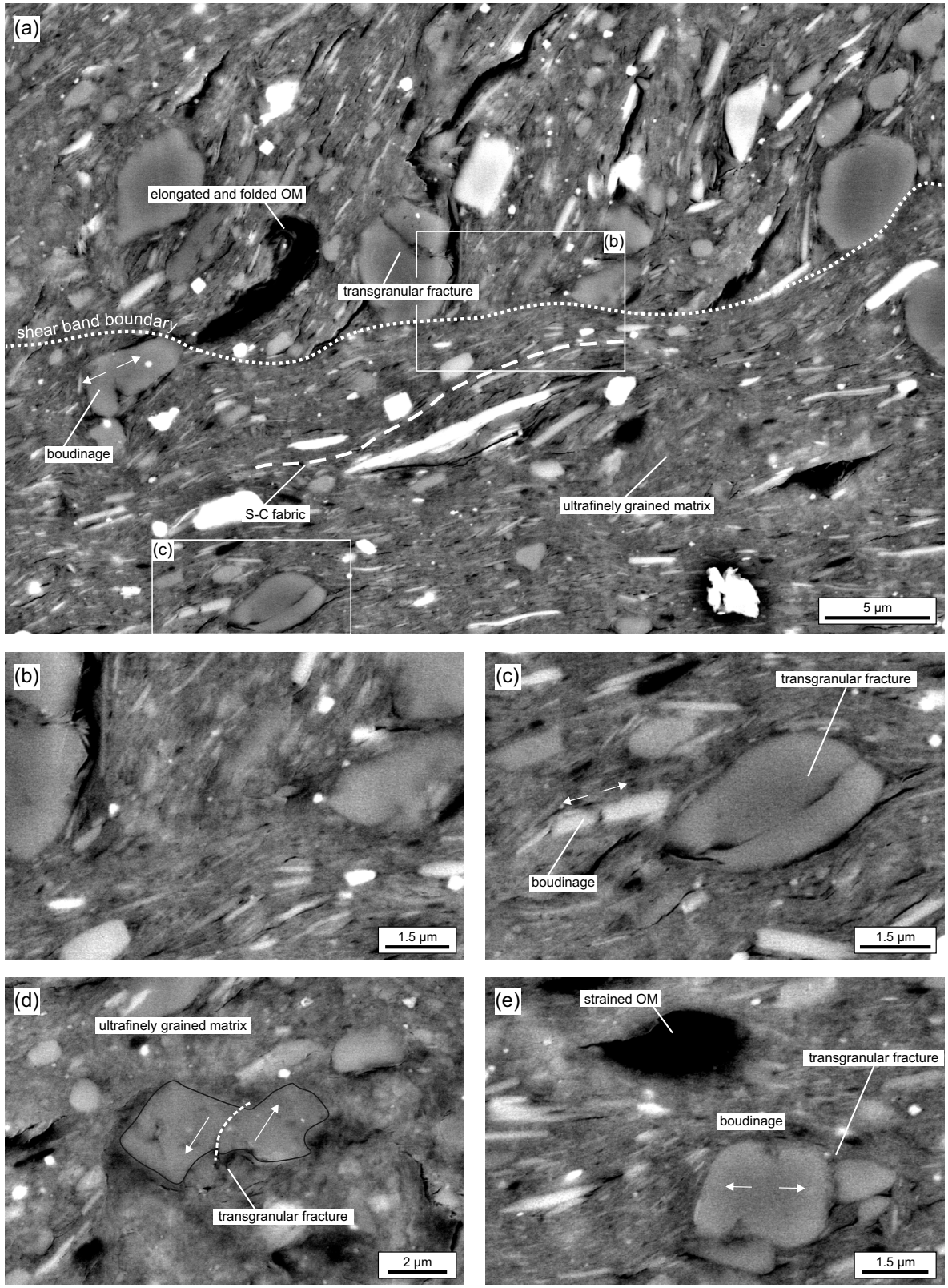

Figure 9. Details of gouge microstructure (sample V15-4; see Fig. 11a, b) with strict foliation discordance (sharp boundary of shear band to Pfoliation domain), transgranular fractures, boudinage grains, strained organic material (OM), micrometer-thin shear zones (b) and ultrafinely grained matrix. All micrographs recorded with a BIB-SEM (BSE).

which suggests a number of small grains positively deviating from the power-law trend of larger grains. The matrix (unsegmented region) makes up $69.3 \%$ of the gouge sample with a clast / matrix ratio of 0.44 (for comparison: $52.9 \%$ is unsegmented in the undeformed sample with a clast / matrix ratio of 0.89; see Fig. 11).

\subsection{Bulk mineral analysis}

A total of 18 X-ray diffraction measurements were performed: 8 on powdered gouge material and 10 on surround- ing wall rock material. All samples are equal in type and quantity of minerals, except for a reduced amount of calcite in gouge. There is no spatial trend in calcite or any other mineral composition towards gouge, as evident from congruent X-ray diffraction patterns in Fig. 15. The boundary between bright wall rock and dark, calcite-reduced gouge is sharp. This is in agreement with our SEM-EDX observations (e.g., Fig. 4c).

The dark color of gouge is not a result of a high amount of organic carbon: one gouge and one wall rock sample show 

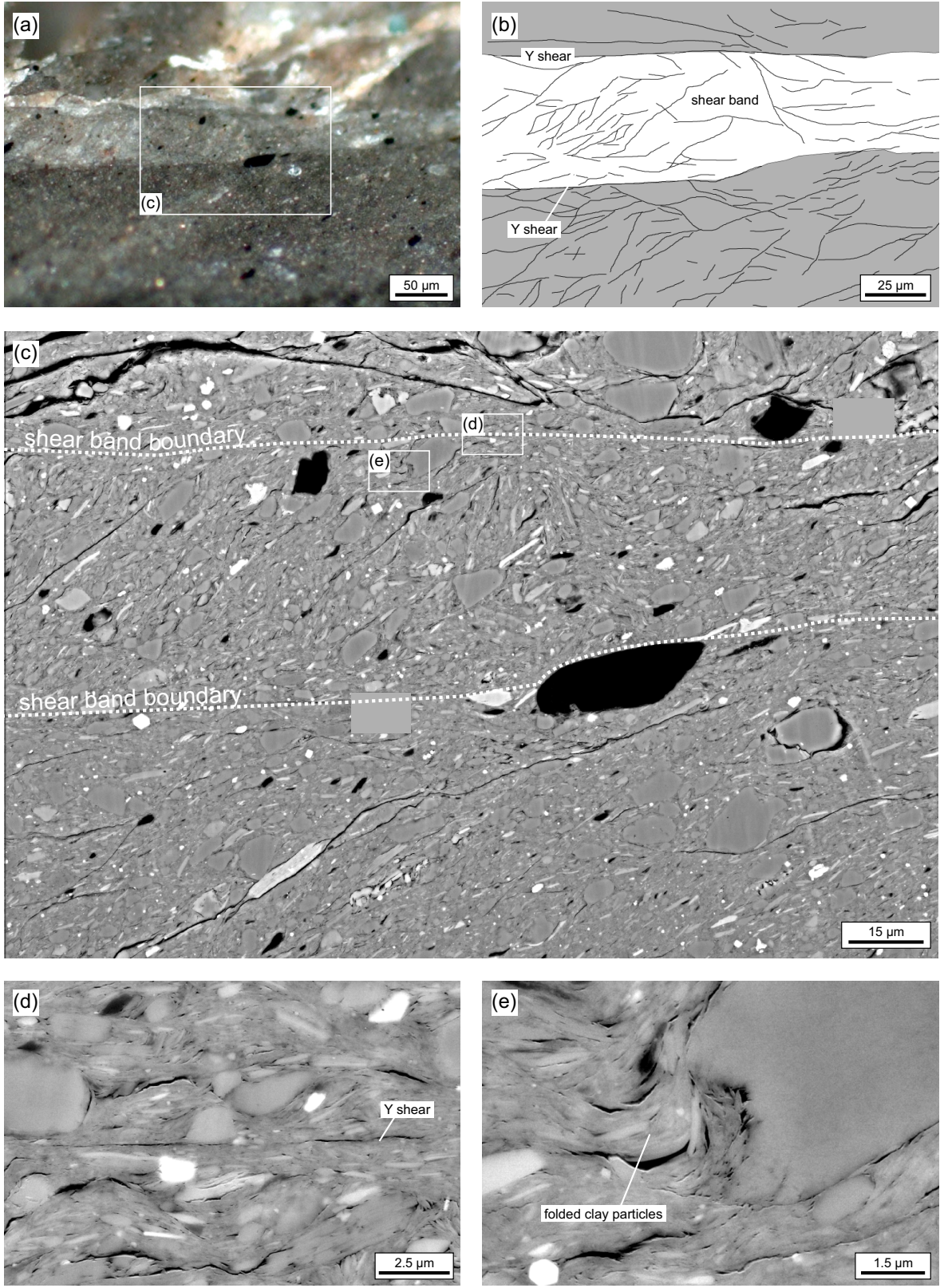

Figure 10. Microstructures of a gouge-internal shear band (sample A1-1) with micrometer-thin Y-shear boundaries (d), strained organic matter (dark grains) and pores in pressure shadow regions of larger grains (e). (a) Reflected light micrograph and (b) sketch of foliations. (c, d, e) BIB-SEM (BSE) micrographs. The shear band is located at the border of gouge with vein-enriched scaly wall rock. See Fig. 5c for location.

similar total organic carbon content $(1.1$ and $1.3 \mathrm{wt} \%$, respectively). These values are consistent with literature on the OPA (Nagra, 2002; Pearson et al., 2003).

Frictional heating in the gouge is not evident from vitrinite reflectance. One dry polished sample containing gouge and wall rock shows vitrinite reflectance ranging from 0.55 to $1.2 \%$, with an average of 0.948 and $0.915 \%$ for the gouge $(N=40)$ and the wall rock parts $(N=70)$, respec- tively. These values are consistent with literature on the OPA at the Mont Terri location (Nagra, 2002).

\subsection{Indicators of deformation mechanisms}

We identified microstructural indicators for different mechanisms: (1) cataclasis and abrasion, (2) frictional granular flow, (3) pressure solution precipitation, (4) neoformation of clay grains and (5) intracrystalline plasticity. 

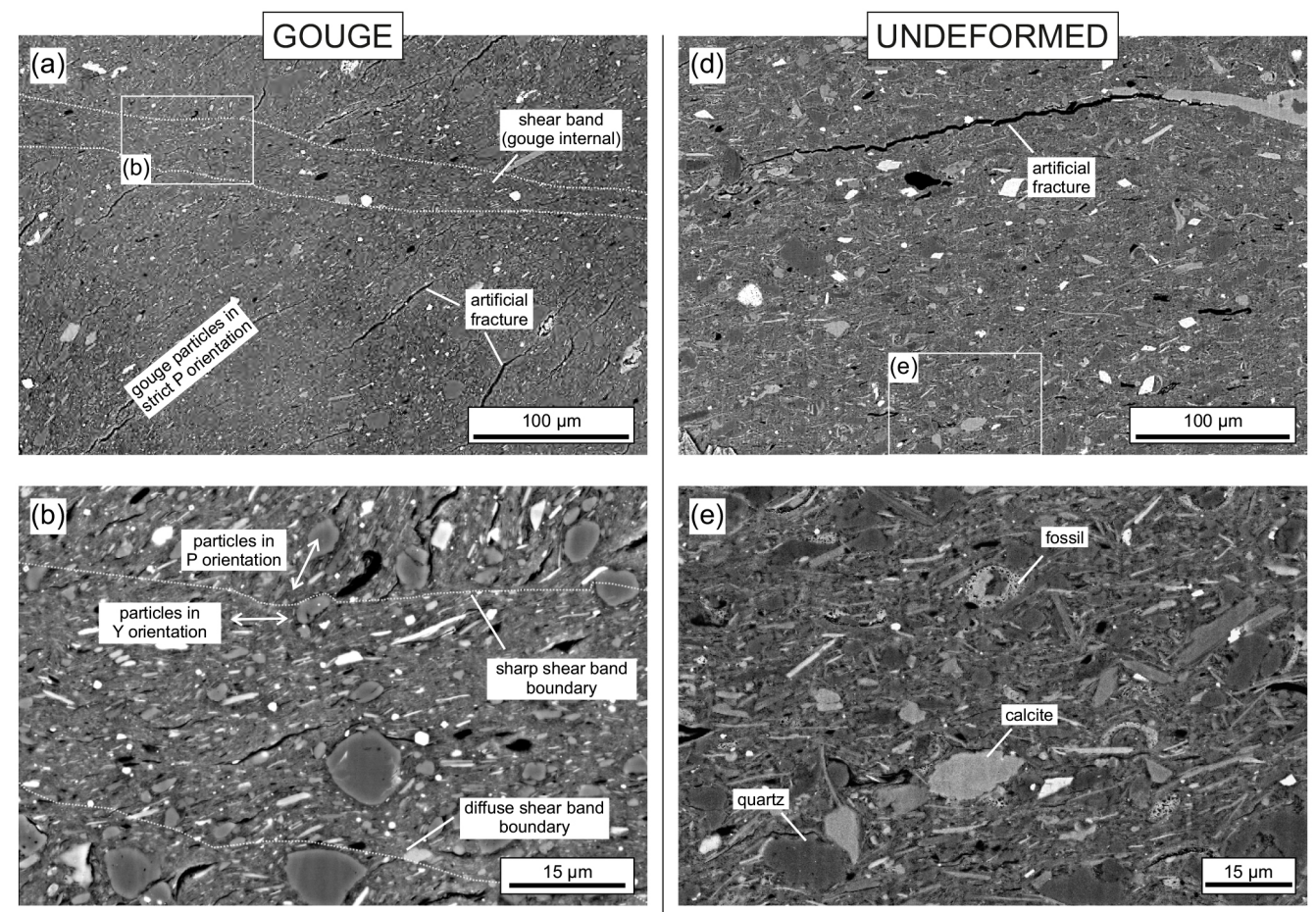

(c)
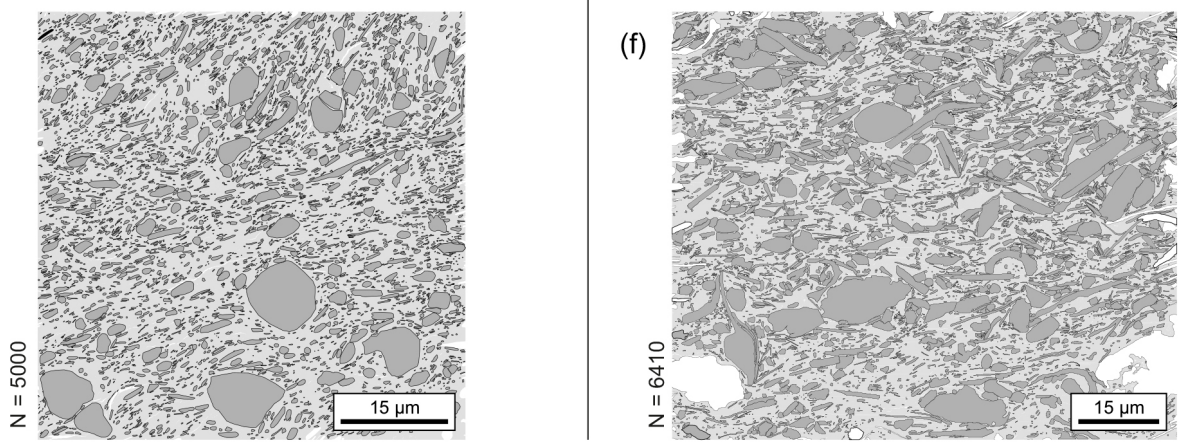

Figure 11. Comparison of the undeformed OPA (right, sample V08) to gouge fabric (left, sample V15-4) with grains in P foliation and with a $30 \mu \mathrm{m}$ wide shear band of differently oriented grains. All micrographs are recorded using a BIB-SEM (BSE). Panels (b) and (e) are insets of panels (a) and (d), respectively. (c, f) Manually segmented grains used in statistical analysis (see Fig. 12). Zoom-in for full detail.

\subsubsection{Cataclasis, abrasion and frictional granular flow}

The shape factor analysis above points to a process that produces rounded grains with smooth boundaries, presumably through an abrasion process perhaps coupled with dissolution (e.g., Fig. 11 and slight shift in circularity shown in Fig. 12d). Moreover, transgranular fracturing and boudinage is abundant in mica, calcite, feldspar and quartz (and/or $\mathrm{SiO}_{2}$ grains; see section below) across several scales (Fig. 9). Figure 16 shows bending and breakage of a mica grain through delamination along the (001) basal planes with progressive break-up of even the smallest grains. Particle breakage can occur along kinks as well (Fig. 14d). Commonly, fractured grain parts are offset so far that they cannot be correlated anymore and the full extent of grain fracturing cannot be quantified (Milliken and Reed, 2010; see Haines et al., 2013).
The preserved high fabric intensity (Fig. 4), the well developed S-C fabric pattern (Fig. 6) and the occasional "mixing" and "injection" appearance of gouge (Fig. 5; see cataclasites in Chester and Chester, 1998; Brodsky et al., 2009; Demurtas et al., 2016) suggest a continuous granular flow, in which individual particles are aligned in response to movement along shear bands and micrometer-thin shear zones. Therein, the individual particles pass by each other through grain boundary sliding (Passchier and Trouw, 2005; Haines et al., 2014), while the void between the grains is filled by the ultrafinely grained matrix (Figs. 9, 14) or, occasionally, by the development of pores in pressure shadows (Figs. 10e, 14d and e). We therefore propose that the ultrafine matrix was significantly weaker than the rest of the gouge, as its small, likely less elongated particles are easy to reorient, possibly aided by 


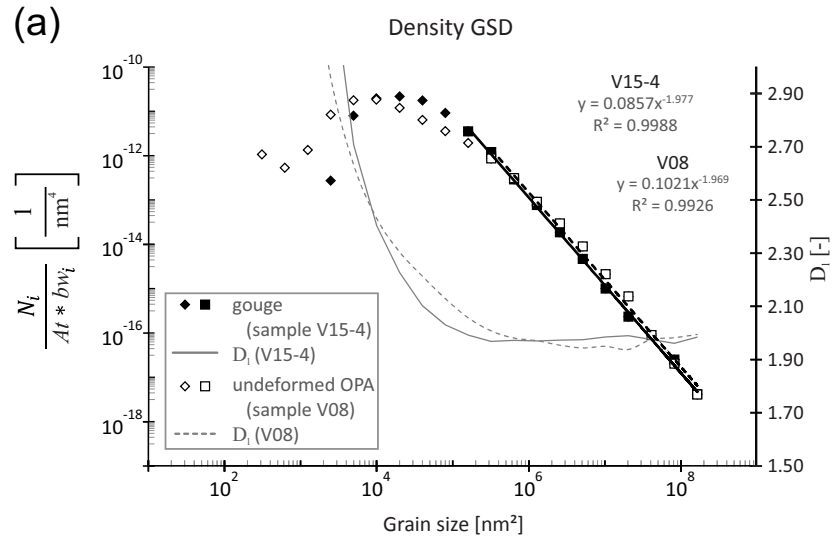

(c)

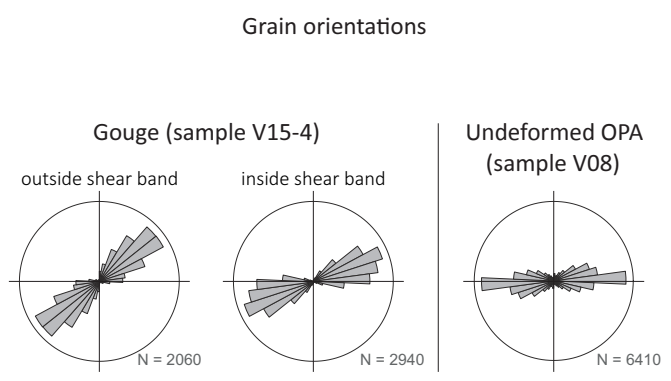

(b)

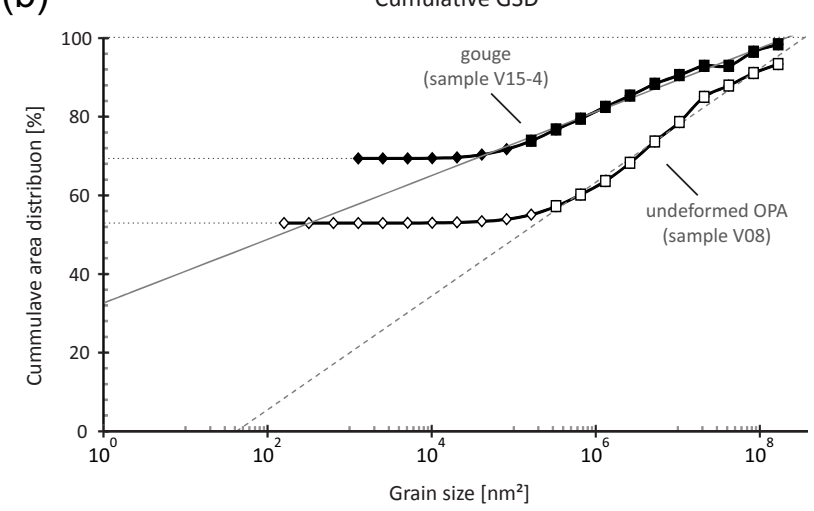

(d)

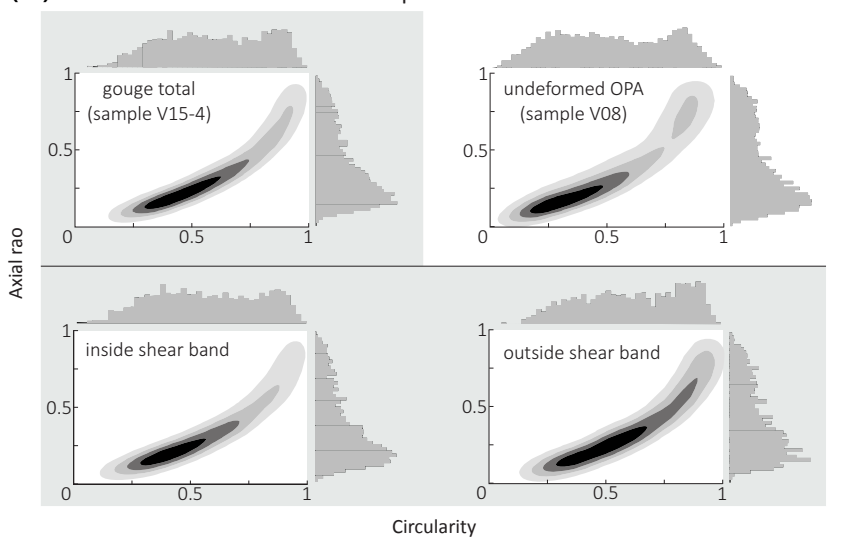

Figure 12. Statistics on grain size, shape and orientation of samples V15-4 (gouge) and V08 (undeformed OPA); see Fig. 11. (a) Density grain size distribution (GSD): grain size vs. number of grains $\left(N_{i}\right)$ noted with respect to bin width $\left(\mathrm{bw}_{i}\right)$ and normalized for the examined area (At); $D_{1}$ : local slope, indicating a deviation from the power-law trend for smaller grain size bins due to resolution limitations (truncation). Boxes: values used in power-law trend calculation; diamonds: values excluded from power-law calculation. Note the parity in density GSD for the undeformed OPA and gouge. (b) Cumulative GSD: grain size vs. cumulative area. Note that the distribution does not sum up to $100 \%$ due to excluding (i) pores and (ii) grains that do not fall completely within the examined area. The curves start depending on the matrix content of the samples, i.e., on the area percentage that cannot be visually divided into segments. Note that a strict extrapolation for the cumulative gouge GSD results in unrealistically small grains (less than one lattice plane distance). Hence, a larger contribution of grains below the BIB-SEM resolution limit is inferred. (c) Grain orientations weighted by the grains' axial ratio. (d) Axial ratio vs. circularity, with the mean center of gouge deviating from the undeformed OPA, indicating an increased smoothness of the gouge grains.

water bound to the nanometer-sized grains. This setting led to a complete loss of preferred orientation of nanoparticles in parts of the gouge (Fig. 14c). However, "(nano)particle rolling", as found in high-velocity tests of synthetic gouge (Han et al., 2011; Chen et al., 2017), might not have had a large impact on gouge weakening in the low-velocity Main Fault. Instead, the matrix likely responded with a lower viscosity to frictional offset along particles oriented face-to-face in micrometer-thin shears (see Jessell et al., 2009). We also note that larger organic matter particles, although strained, still appear stronger than the matrix (Fig. 10) and could be used as a strength gauge (Eseme et al., 2007).

\subsubsection{Diffusive mass transport (pressure solution precipitation and clay neoformation)}

In the sections above, we reported strongly reduced calcite content for gouge, while in the wall rock calcite veins and calcite patches are abundant. If the alternative clay-smear explanation (discussed below) can be excluded, this is a critical discovery that indicates large-scale removal through pressure solution of calcite from the gouge and perhaps crystallization in the nearby microveins (Laurich et al., 2014, 2017; Clauer et al., 2017).

Isotope and rare earth element analyses of gouge material show differences from the undeformed OPA, from veins and from scaly clay aggregates from the Main Fault, suggesting 




Figure 13. Comparison of the undeformed OPA (right, sample V08) to gouge porosity (left, sample V15-4). All micrographs are recorded using a BIB-SEM (SE detector). (c, f) Same location as panels (b) and (e) recorded with a BSE detector. Note the decreased visible porosity in gouge. Larger cracks in gouge are interpreted as artifacts. Bright grain to the left in panels (e) and (f) is part of a calcite fossil.

that gouge interacted with fluids chemically different from those in the other parts of the Main Fault (Clauer et al., 2017).

Figure 3 shows a slickenside surface of a broken gouge sample. At high magnifications, the smoothly polished surface shows nanometer-sized clay particles. These nanometersized clay particles, also reported in the gouge matrix in TEM (Fig. 14b), may result from neoformation, as described for gouge in other studies (Vrolijk and van der Pluijm, 1999; Sasseville et al., 2008; Schleicher et al., 2010; Warr et al., 2014). Particularly concerned with illite neoformation in the Main Fault, Clauer et al. (2017) report preliminary K-Ar ages of nanometer-sized illites from the gouge material that coincide with the inferred onset of the Main Fault (9-4 Ma).

Above, we propose that the nanometer-sized clay grains could be detrital material and/or a result from cataclasis and/or neoformation. Additionally, they could derive from clay mineral transformation. This mechanism has been re- ported for the transformation of smectite and/or mixed-layer illite-smectite to illite in other fault gouges (e.g., Vrolijk and van der Pluijm, 1999; Dellisanti et al., 2008). The shaly OPA facies contains 5-20 wt \% mixed-layer illite-smectite (Pearson et al., 2003). Similar to the setting of the Main Fault, Casciello et al. (2011) report an illitization for an upper-crustal, low-offset fault in a mudstone protolith. They argue that illitization can occur localized in shear bands at low P-T conditions and without fluid-rock interaction. Further, and similar to our observations, they report darkened shear zones and relate this to the localized illitization of the fault rock. However, we do not have sufficient evidence for such an illitization process in the OPA, as we did not design our X-ray diffraction measurements to spot differences in smectite and illite contents and our SEM-EDX measurements yield no element contrast for the micrometer-thin bands. 

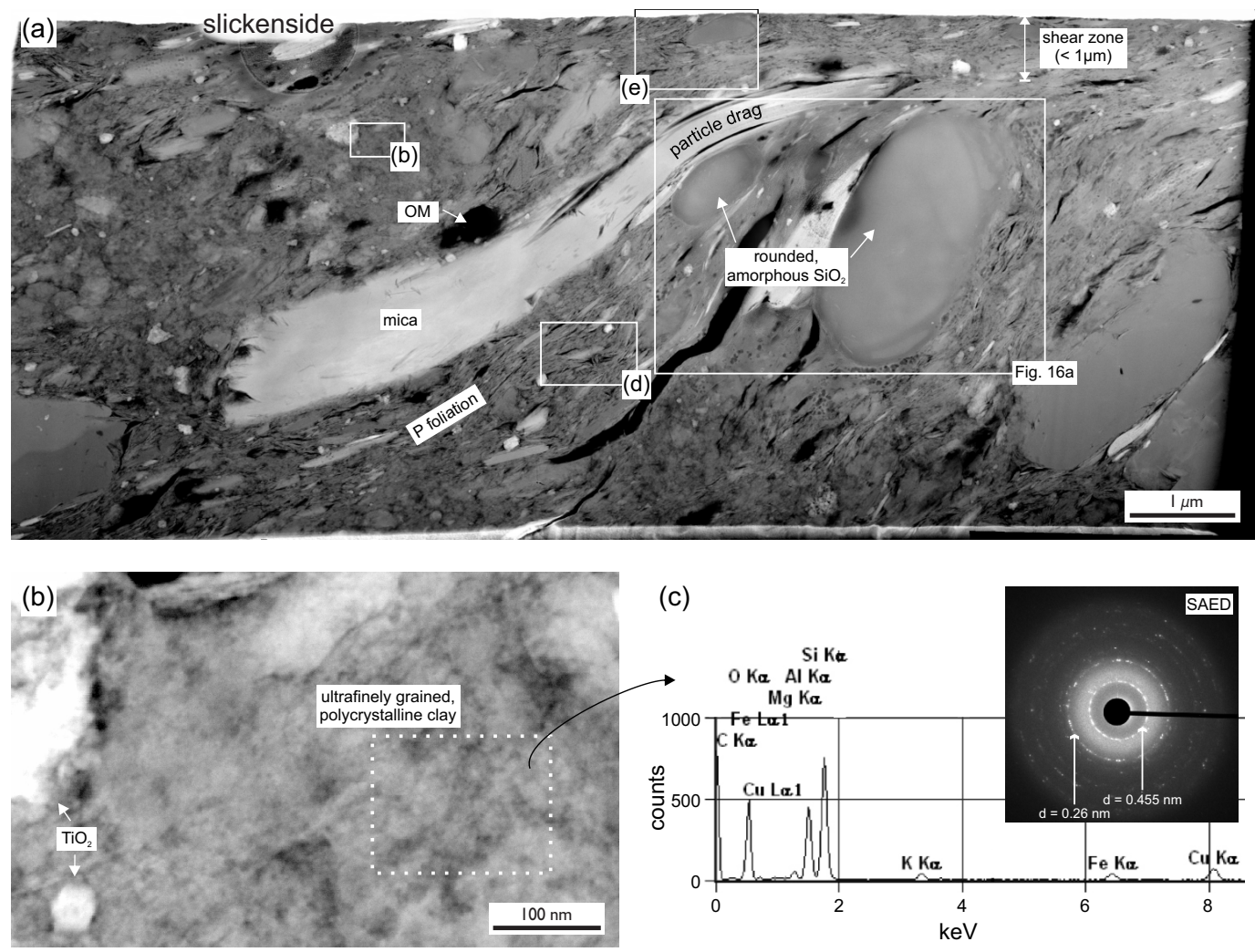

(c)
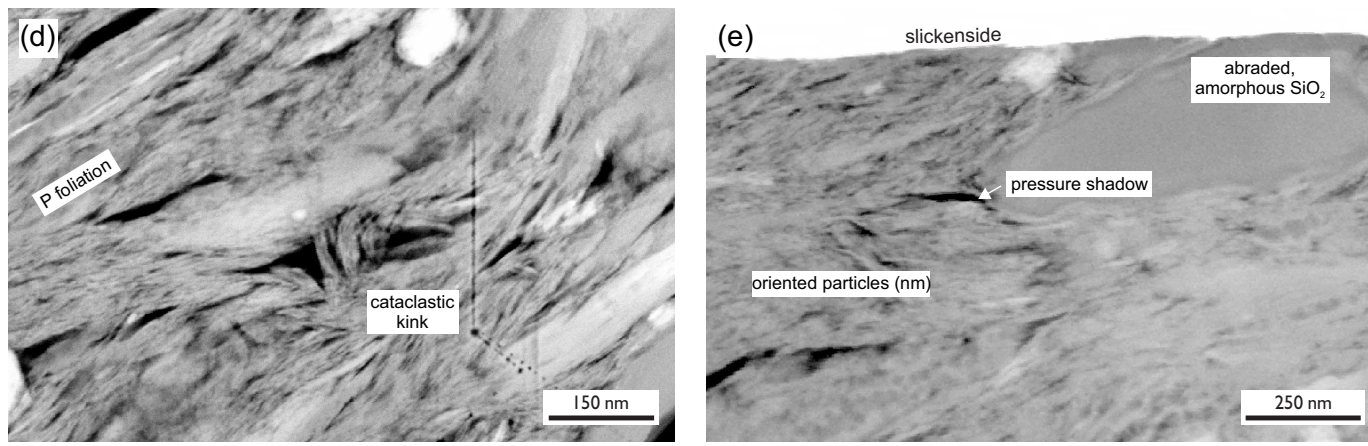

Figure 14. Microfabric of gouge (sample V15-FIBgouge1) visualized with TEM methods. (a) HAADF micrograph containing a gougeinternal micrometer-thin shear zone (e); P foliation (d); pores in pressure shadow regions (e); cataclastic kink (d); rounded, amorphous $\mathrm{SiO}_{2}$ grains (also Fig. 16), a dragged mica and unresolvable small, ultrafinely grained gouge matrix (b). (c) EDX and selected area electron diffraction from the region shown in panel (b), indicating that the matrix is polycrystalline clay. See text for details.

The gouge comprises well rounded, anhedral, amorphous $\mathrm{SiO}_{2}$ grains, shown by the diffuse selected area electron diffraction pattern of one $\mathrm{SiO}_{2}$ grain shown in Fig. 16a. We consider that amorphous $\mathrm{SiO}_{2}$ is unlikely an artifact of the focused-ion-beam preparation procedure as the less stable clay minerals in the lamella are preserved. Moreover, an ionbeam-induced decrease in diffraction efficiency of quartz has been found to be minor (Fu and Bryan, 2005) and a complete amorphization is implausible. Consequently, the amorphous $\mathrm{SiO}_{2}$ may have formed through precipitation from hydrothermal fluids. Amorphous $\mathrm{SiO}_{2}$ has not been reported for the OPA before (e.g., Pearson et al., 2003; Lerouge et al., 2014).
Gaucher et al. (2003) even concluded that amorphous silica was not found in the OPA and that neoformed quartz cement formed during diagenesis is well preserved with un-corroded crystal planes. The mineral assemblage of amorphous material and clays is typical in several gouge localities, although in more mature fault gouges (Power and Tullis, 1989; Di Toro et al., 2004; Hadizadeh et al., 2012; Janssen et al., 2013; Kirkpatrick et al., 2013; Kameda et al., 2017). 


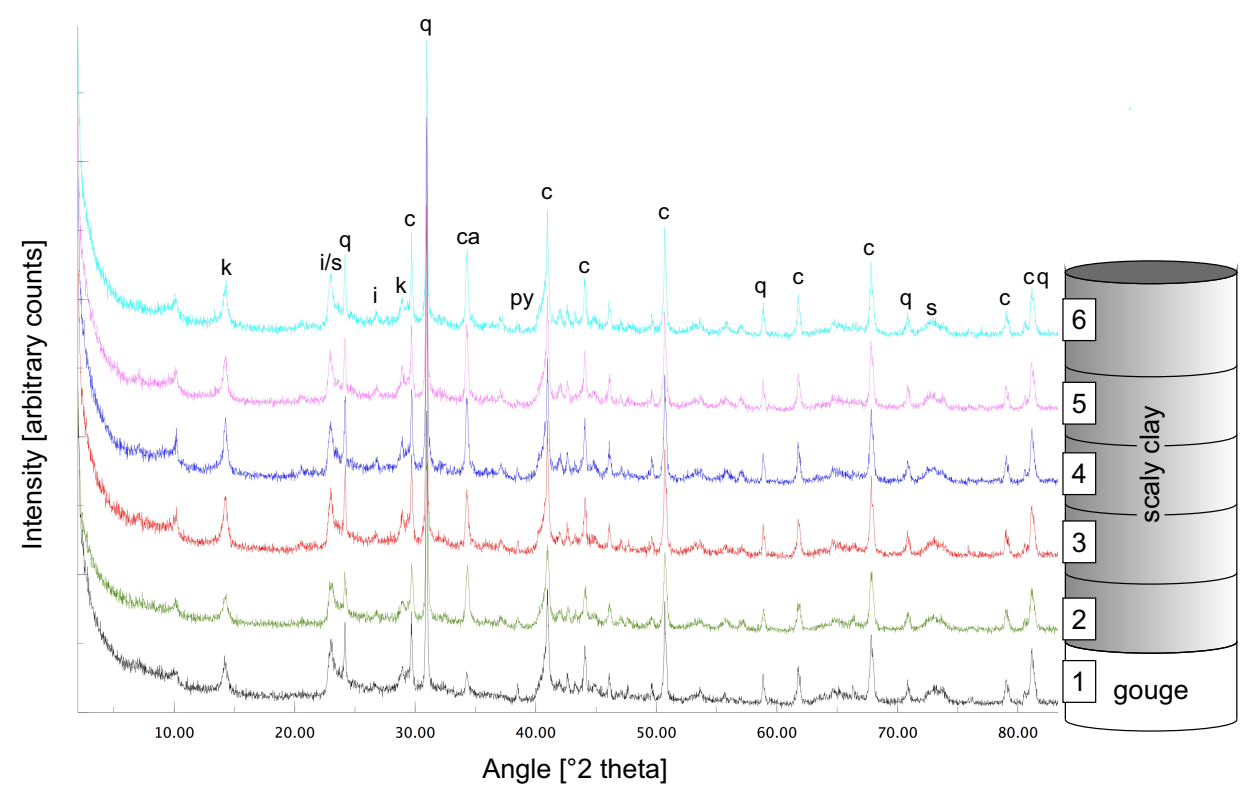

Figure 15. Stack of six X-ray diffraction patterns from sample BPS12-4. Pattern 1 belongs to a gouge layer, pattern 2 is $1 \mathrm{~cm}$ from gouge, pattern 3 is $2 \mathrm{~cm}$ from gouge and so forth (sketched). Note that there is no obvious change in the pattern except a reduced calcite peak in gouge. Measurements were performed on a Huber MC9300 diffractometer using CoKa radiation produced at $40 \mathrm{kV}$ and $40 \mathrm{~mA}$. k: kaolinite; I: illite; s: smectite; q: quartz; ca: calcite; py: pyrite; c: corundum (20 wt \% added as internal standard).
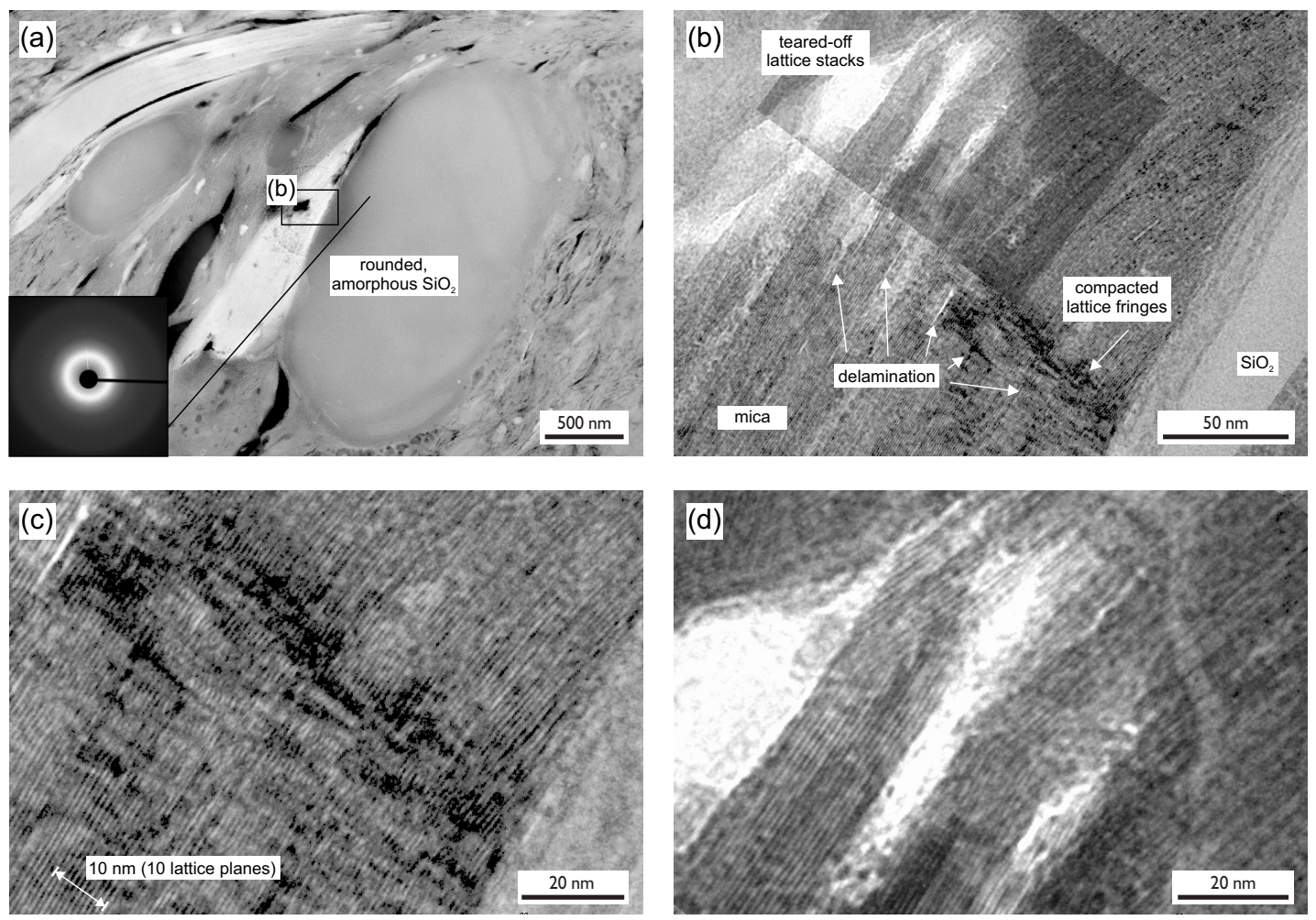

Figure 16. Microstructural details of gouge shown in Fig. 14 (sample V15-FIBgouge1). (a) TEM (HAADF) micrograph and selected area electron diffraction pattern of amorphous $\mathrm{SiO}_{2}$. (b, c, d) HR-TEM (BF) insets of panel (a) showing delamination and breakage of a mica(?) grain. See text for details. 

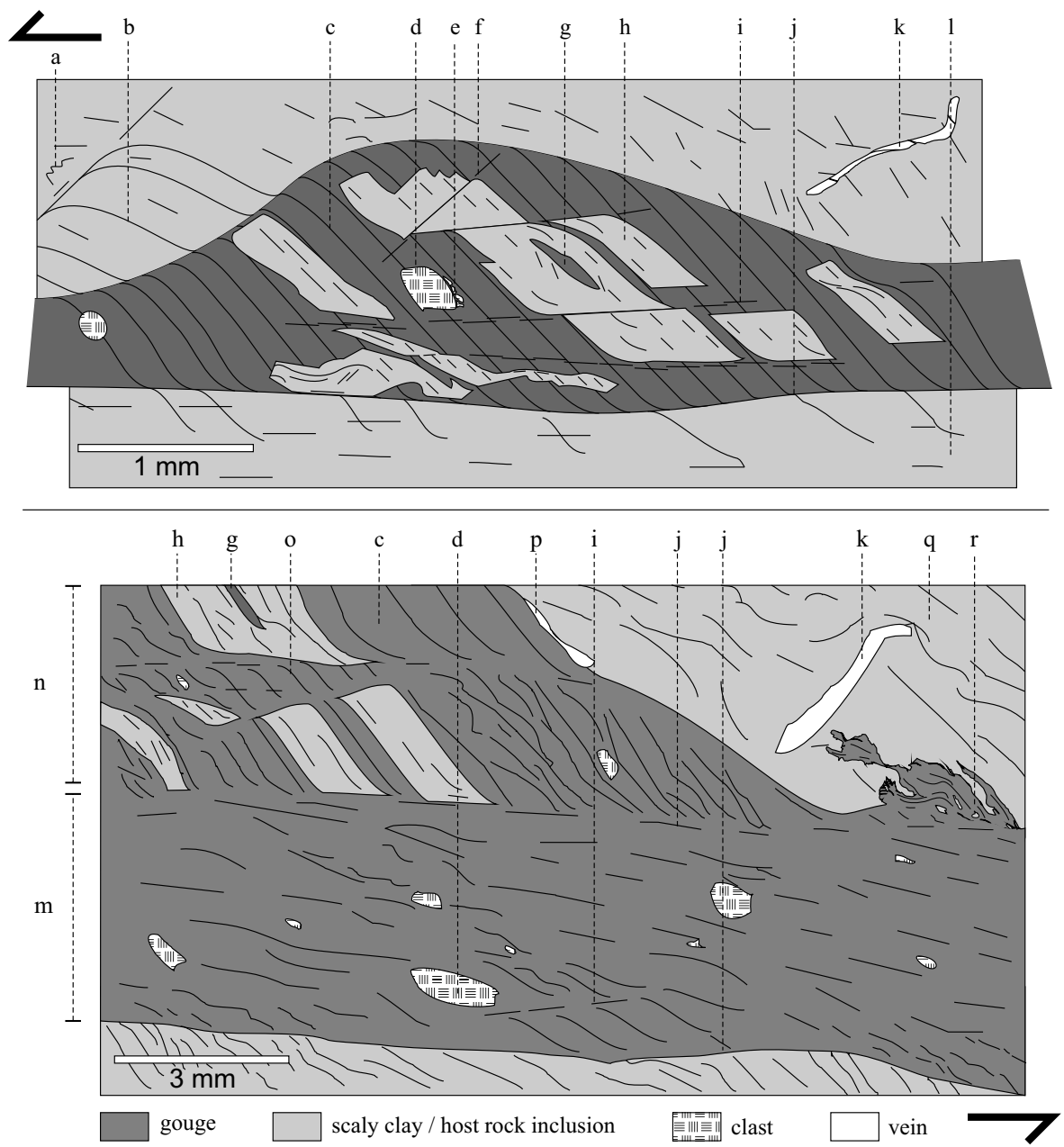

Figure 17. Generic sketches of gouge type 1 (top) and type 2 (bottom) summarizing all microstructural elements found (after Laurich, 2015). (a) Transpressional folding of foliations (occasional). (b) Sigmoidal foliation (resembling S-C fabric), fabric intensity higher than in other areas of scaly clay. (c) Intense uniform P foliation inside gouge domains (always). (d) Clast (pyrite, quartz, feldspar, calcite) parallel to subparallel to P foliation. (e) Spalled fragments of clast (common in calcite clasts). (f, i, j) Localized shear bands, always synthetic: (f) in R orientation, rare in gouge with low-angle $\mathrm{P}$ foliation, (j) in Y orientation, (i) foliation parallel to gouge domain boundary (always if boundary is parallel to shear sense). (g) Gouge lens inside host rock inclusion (occasional). (h) Strained host rock inclusion (often). (k) Strained and fragmented vein in R orientation (occasional). (l) Scaly clay fabric with anastomosing foliation (no S-C foliation). (m) Type 2 gouge domain with $\mathrm{P}$ foliation subparallel to shear sense, no host rock inclusions and more clasts than in (n). (n) Type 1 gouge domain with P foliation oblique to shear sense does contain host rock inclusions. (o) S-C fabric (common in type 1 gouge, rare in type 2). (p) Vein parallel to gouge boundary (occasional). (q) Scaly clay with foliation in P orientation. (r) Gouge "intrusion" pattern in wall rock.

\subsubsection{Intracrystalline plasticity}

Intracrystalline plasticity of phyllosilicates is proposed as a deformation mechanism in clay (Urai and Wong, 1994). However, it is the most difficult one to observe: permanent deformation without fracturing is thought to occur mostly along the clays' (001) basal planes, producing a crystal lattice hardly distinguishable from the educt (Warr and Cox, 2001; Warr et al., 2014). Figure 16 shows grains delaminated along (001), suggesting intracrystalline plasticity or fracturing parallel to (001) (see Goodwin and Wenk, 1990). Other indicators for intracrystalline plasticity are the frequently folded (e.g., Fig. 10e) and bent (e.g., Fig. 14a) clay particles, although elastic deformation may also cause this (Wenk et al., 2008; Kanitpanyacharoen et al., 2015). In a nano-indentation test to determine the elasticity of single phyllosilicate minerals, Zhang et al. (2010) suggest measurement artifacts caused by intracrystalline plasticity beneath the indenter tip. Particle bending next to shears can also be seen in TEM: Figure 14 displays a $500 \mathrm{~nm}$ thick, dragged mica.

Moreover, $\mathrm{SiO}_{2}$ grains in gouge are frequently boudinage (e.g., Fig. 10a), a result of strain likely induced by a plastic deformation of the surrounding gouge matrix (compare also with boudinage mica in Fig. 10c). $\mathrm{SiO}_{2}$ grain cusps that form 
during this process are filled with clay minerals of the gouge matrix, while grains with transgranular fractures often show unfilled pore space (e.g., $\mathrm{SiO}_{2}$ grain in Fig. 10c).

\subsection{Results summary}

Gouge comprises a variety of microstructures (Fig. 17). It occurs as a continuous, dark, finely grained band at the upper boundary and in a few samples from within the scaly clay part of the Main Fault. It shows a reduction in calcite compared to the brighter wall rock and can be separated into two types. Type 1 shows a high P-foliation angle to shear zone dip, bright wall rock clasts and S-C foliation. Type 2 shows a lower P-foliation angle to shear zone dip, no wall rock clasts and several grain clasts. Both types have internal micrometerthin shear zones and wider shear bands $(<50 \mu \mathrm{m})$ mostly in the R, P and Y orientations. We infer that offset was accommodated mostly along these shears, while gouge between responded in a passive, plastic reorientation of grains in an ultrafinely grained matrix acting as a solid lubricant. There are indicators for all major deformation mechanisms. Both gouge types can be classified as "foliated" (sensu Cladouhos, 1999a).

\section{Discussion}

We can envisage two very different mechanisms for the formation of the gouge in the Main Fault: (a) extreme reworking of the OPA with removal of calcite during deformation and (b) clay smear. It is possible that a combination of these mechanisms has acted. We will discuss both hypotheses in the following sections.

\subsection{Clay smear from a source layer}

It is possible that gouge developed (partly) through clay smear from a calcite-free source layer (sensu Vrolijk et al., 2016).

However, arguments against a smear-only hypothesis are that (i) such a source layer in the faulted stratigraphy $(<80 \mathrm{~m})$ of the Main Fault has not yet been identified (there has not been a focused search for it), (ii) there is a parity in mineral composition and (iii) there is a parity in density GSD in gouge and the undeformed OPA for grains $>10000 \mathrm{~nm}^{2}$ (Fig. 12), and (iv) geochemical studies indicate fluid-driven mineral trans- and neoformations contemporaneous to the inferred tectonic activity (Clauer et al., 2017). Still, clay smear from a source layer could have acted, e.g., when several thin source beds were truncated and linked up to yield sufficient gouge material. Dark, optically gouge-similar, beddingparallel bands are known from other localities in the MT URL (Fig. 18). A fine smear-in from those with additional fluid-rock interactions appears unlikely but feasible.

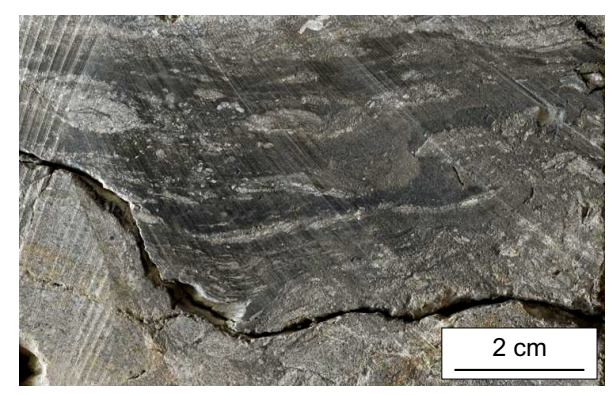

Figure 18. Photograph of dark, macroscopically gouge-similar, bedding-parallel bands from drill core BDB-1. This is to indicate that, contrary to the hypothesis of authigenic gouge generation, gouge could be allogenic, being smeared-in from such dark bands. Next to the Main Fault, however, those bands are not reported. See text for details.

\subsection{Fluid-assisted reworking of the protolith}

An alternative hypothesis is that the spatial relation of undeformed fabric, scaly clay and gouge types 1 and 2 is also a progressive relation: gouge was generated from the highly deformed OPA, with gouge type 2 generated from type 1 . This scenario, however, involves a complex interference of micromechanical processes, including external fluids, and it would be strongly supported by the sporadic occurrence of transition-stage microstructures, which are not clearly recognizable. Below, we describe the processes in this scenario.

\subsubsection{Stage 1 - development of scaly clay (see Laurich et al., 2017)}

In an earlier publication, we have shown that undeformed protolith develops into a scaly clay fabric, with an increasing density of micrometer-thin, nonporous shear zones and microlithons. The generation of scaly clay results from progressive development of new micrometer-thin shear zones in between relays, likely enhanced by a combination of two mechanisms: (1) geometric locking of existing micrometerthin shear zones and (2) local fluid pressure increase, caused by the pore water expulsion from the nonporous shear zones (Vannucchi et al., 2003; Laurich et al., 2017). The frequent veins along micrometer-thin shear zones are evidence of external fluid flow when the Main Fault was active (de Haller et al., 2014; Clauer et al., 2017). Therein, the micrometer-thin shear zones have been interpreted to have acted as temporary fluid conduits with nonporous, impermeable side walls. This assumption is supported by geochemical studies (element and isotopic analyses), stating a limited time of fluid flow in the Main Fault that did not markedly affected the host rock and its pore-water composition (Clauer et al., 2017; Mazurek and De Haller, 2017). Our finding of nonporous, micrometer-thin shear zone walls relates to several studies reporting fault-parallel fluid flow, wherein permeabilities perpendicular to the fault are several orders of magnitude lower 
than parallel to it (e.g., Arch and Maltman, 1990; Caine et al., 1996; Crawford et al., 2008; Warr et al., 2014).

\subsubsection{Stage 2 - development of type 1 gouge from scaly clay}

The boundary of scaly wall rock to gouge is always strictly sharp, without any gradual transition in porosity, particle size, particle shape or calcite content - not even on a SEM scale. However, the sigmoidal wall rock clasts and their occasional feather-like appearance (Figs. 7, 8) suggest a progressive rework of host rock into gouge.

\section{Development of $\mathbf{P}$ foliation}

Numerous studies propose a passive reorientation of grains between movement-accommodating principle shear zones (Morgenstern and Tchalenko, 1967; Cladouhos, 1999a, b; Haines et al., 2013), i.e., grains rearrange towards a P orientation due to offset along $\mathrm{C}$ and $\mathrm{Y}$ shears (see Lin, 2001; Bigi, 2006).

\section{Calcite dissolution}

The reorientation process is proposed to comminute (fossil) calcite between the rearranging grains and this promotes the calcite dissolution by fluids, perhaps related to a temporary permeability increase from local dilation in restraining bands (similar to Figs. 10e and 14e) until a static, high-intensity foliation is reached and the fault is resealed (see Takizawa and Ogawa, 1999; Holland et al., 2006; Bock et al., 2010). Moreover, calcite dissolution is enhanced by the onset of grain size reduction (Rutter and Elliott, 1976; Gratier et al., 2014).

\section{Generation of nanometer-sized clay grains}

Matrix material, i.e., nanometer-sized clay grains (Fig. 14b), is more abundant in gouge than in the undeformed OPA. It may be generated by cataclastic delamination processes and/or by neoformation. A model for authigenic gouge evolution from fluid flow along preexisting shears was also proposed elsewhere (e.g., Solum, 2003; Schleicher et al., 2010; Janssen et al., 2013; Haines et al., 2014; Warr et al., 2014; Buatier et al., 2015). In experiments, cataclastically generated gouges yield power-law GSDs with exponents $(D)$ increasing with strain until a static value of $D \sim 2$ is reached. Henceforward, abrasion and wear dominate over grain splitting (e.g Sammis and King, 2007; Mair and Abe, 2011). For the OPA, undeformed material shows $D=1.97$ already in existence, in parity with the gouge $(D=1.98)$. Accordingly, gouge might not develop a larger $D$ value with strain but only an increase in smallest grains by abrasion. The GSD of OPA gouge is inferred to increase in $D$ for grains below the resolution limit, i.e., grains $<10000 \mathrm{~nm}^{2}$ have a large contribution to the total GSD. Conversely, for synthetic quartz gouge, Keulen et al. (2008) report a decrease in $D$ for grains below a radius of $1.1 \mu \mathrm{m}$ (so-called "grinding limit"; see Kendall, 1978). This discrepancy, combined with geochemical results (Clauer et al., 2017), suggests that neoformation contributes significantly to the generation of nanometer-sized clay grains, even though abrasion and delamination of larger grains occurs too (see Fig. 16).

\section{Origin of amorphous $\mathrm{SiO}_{2}$}

The origin of amorphous $\mathrm{SiO}_{2}$ grains that we found in the gouge (Fig. 14) remains enigmatic. Either it formed from $\mathrm{Si}$ rich fluids or it is of detrital origin, smeared from a source layer. However, mineralogical analyses have not found any amorphous material in the OPA (Lerouge et al., 2014; see above). Potentially, the grains were rounded during the gouge evolution: Kameda et al. (2017) consider that hydrous opal$\mathrm{CT}$ is highly deformable via pressure solution creep at rather low driving stresses of the order of kilopascal. This consideration might hold true for the rheology of the boudinage $\mathrm{SiO}_{2}$ grains in Fig. 9.

Stage 2 results in gouge type 1 fabric that is illustrated by Fig. 7, showing the $\mathrm{P}$ orientation of mineral foliations and (not yet reworked?) host rock clasts. Note that the clasts are separated along P-oriented dark gouge: an indicator for progressive rework of host rock into gouge material.

\subsubsection{Stage 3 - development of type 2 gouge}

Similar to scaly clay aggregates, an S-C fabric is visible in developed gouge type 1, too (Fig. 6). This fabric suggests a continuing application of the processes of stage 2 to generate the more mature type 2 gouge, with the dissolution of all remaining host rock clasts and further dissolution of calcite. Once developed, the P-foliation angle to shear direction is not a result of simple shear strain (i.e., offset), but of the amount of pure shear (Cladouhos, 1999a, b): volume loss through dissolution of calcite potentially resulted in a decrease in shear zone width, lowering the P-foliation angle. Thus, the differing dissolution of calcite likely causes the differing $\mathrm{P}$ foliation of both gouge types (Fig. 6b). From geochemical analysis, Clauer et al. (2017) propose gougeexclusive sulfate and/or phosphate-rich fluids that enhance the localized calcite dissolution in gouge.

We propose that the gouge development is more effective in the early stage 2 , followed by a change in micromechanical behavior, in which frictional granular flow of the existing gouge material and sliding along micrometer-thin $\mathrm{R}$ and Y shears dominate over further rework of the host rock (see Guo and Morgan, 2007).

\subsection{Physical rock properties of gouge}

The strong clay grain alignment in micrometer-thin shears suggests a low residual friction coefficient along (001) lattice planes once faulting is initiated (see Collettini et al., 2009; Mizoguchi et al., 2009). Ultrafine clay particles, the 
strict $\mathrm{P}$ foliation, the strong calcite reduction, the strained but not fractured organic matter and the well rounded amorphous $\mathrm{SiO}_{2}$ grains in gouge emphasize a rate-dependent component of viscous deformation with distributed brittle shear along $\mathrm{R}$ and $\mathrm{Y}$ shears. Using a BIB-SEM, we find the porosity of gouge to be lower than the porosity in the undeformed OPA $(<18 \%)$. However, a large population of the smallest pores beyond the resolution limit of this method $(<10 \mathrm{~nm})$ is considerable. The micrometer-thin shears are found to be nonporous, even for pores $<10 \mathrm{~nm}$ using TEM, potentially enabling a trap of high fluid pressures inside gouge (see Zhang et al., 2001; Cuss et al., 2011). Such local high fluid pressures promote further strain localization, which likely occurred progressively due to the interplay of pore pressure generation, tectonic stress buildup and (slow) pore pressure dissipation. The occasional "injection" appearance of gouge (Fig. 5) supports the hypothesis of trapped high fluid pressures in gouge (see "fluidization"; e.g., Chester and Chester, 1998; Fondriest et al., 2012; Rowe et al., 2012). Therein, gouge injection occurs into less pressurized host rock fractures where the gouge-bounding micrometer-thin shear zone failed. Contrary to rather brittle, i.e., spontaneous, localized failure of the OPA in common laboratory experiments, the in situ gouge fabric suggests a long-term creep behavior and distributed shear along micrometer-thin shear zones (see "dry" experiments in Giger et al., 2008; Desbois et al., 2017), where fluid flow is drastically inhibited perpendicular to shear, but temporarily enhanced parallel to shear inside the gouge. In direct shear experiments, Bakker et al. (2017) showed for synthetic OPA gouges that a clay-enriched gouge has a lower friction coefficient than gouge with an unaltered OPA composition. Thus, as the gouge from the Main Fault shows a high content of clay matrix compared to the undeformed OPA, we expect the natural gouge to be mechanically weak, i.e., the gouge requires a lower shear stress to induce strain than the undeformed OPA. Through calcite dissolution in gouge, larger, competent calcite grains are removed, which promotes the formation of micrometer-thin shear zones, lowers the gouges' porosity and hinders gouge-perpendicular permeability. The effects could lead to gouge-internal fluid overpressure, causing further gouge weakening (see injection patterns stated above).

\section{Conclusion}

We described the microstructure of natural, upper-crustal fault gouge from the low-offset Main Fault in the Mont Terri rock laboratory (Switzerland), mainly using optical and electron microscopy techniques. We inferred a complex interplay of deformation mechanisms and thus provide insight into the low-rate in situ deformation behavior in the OPA. Our findings can be summarized as follows.
Gouge sharply stands out as a dark (calcite poor), thin $(<2 \mathrm{~cm})$, continuous band at the upper Main Fault boundary and as isolated patches within neighboring scaly clay aggregates. It comprises two fabric types, differing in P foliation, that both show internal micrometer-thin, nonporous shear zones in $\mathrm{R}$ and $\mathrm{Y}$ orientation. Gouge has a higher amount of clay matrix than the undeformed OPA. Using TEM, it can be seen that the gouge matrix consists of nanometer-sized clays with a random orientation, while larger grains show a strong fabric intensity in $\mathrm{P}$ foliation. We found amorphous, well rounded $\mathrm{SiO}_{2}$ in the gouge. The SEM-visible porosity of gouge is strongly reduced compared to the undeformed OPA; however, an increased porosity for gouge from pores smaller than the SEM resolution limit (see Orellana et al., 2016) is possible.

We found indicators for all major deformation mechanisms, including neoformation of clays, pressure solution of calcite, cataclasis and abrasion, and frictional granular flow. The interplay of these mechanisms suggests a low-rate, progressive deformation of gouge. Our microstructural interpretations of deformation mechanisms are in concert with recent geochemical solute-transport studies (Clauer et al., 2017; Mazurek and De Haller, 2017).

We present two very different hypotheses for the evolution of the gouge: (1) fluid-mediated reworking of the undeformed OPA and/or (2) clay smear from a (yet to be identified) calcite-poor source layer. We favor hypothesis (1), as the $\mathrm{S}-\mathrm{C}$ fabric in gouge type 1 suggests a progressive rework of the protolith. This hypothesis would be supported by the occurrence of transition-stage microstructures, which, however, are not clearly recognizable. A combination of both hypotheses is considerable, too.

We consider that in situ, the clay-enriched gouge is weaker than the undeformed OPA and exhibits a viscous rheology with distributed shear along micrometer-thin shear zones. The viscous rheology is inferred from several timedependent mechanisms, as indicated by strong calcite reduction, high nano-particle abundance, strained but not fractured organic matter, and a fluid-like injection pattern into the wall rock.

Future work on OPA gouge should include rotary shear tests of the undeformed OPA to record the fabric development and rheology at large strains. The results could be compared with our findings to infer the impact of processes that are not fully reproducible in the laboratory, such as fluid interactions and low strain rate.

Data availability. Underlying statistical data for this paper can be found in the Supplement.

The Supplement related to this article is available online at https://doi.org/10.5194/se-9-1-2018-supplement. 
Competing interests. The authors declare that they have no conflict of interest.

Acknowledgements. We thank Uwe Wollenberg and Pieter Bertier for performing and discussing the X-ray diffraction analysis. We thank Arne Grobe for providing the vitrinite reflectance and organic carbon measurements. Norbert Clauer and Isabelle Techer helped by providing valuable geochemical data of the study area and by discussing fluid-rock interactions. Jan von Harten and Wiebe Förster are thanked for their excellent help in particle segmentation. Swisstopo and the Mont Terri Consortium are thanked for continued interest and financial support. The article processing charge was funded by the Federal Institute for Geosciences and Natural Resources (BGR). Luca Smeraglia and André Niemeijer provided helpful comments on an earlier version of this paper. We thank Jafar Hadizadeh and the anonymous reviewer for their excellent and constructive criticism of the paper.

Edited by: Renée Heilbronner

Reviewed by: Jafar Hadizadeh and one anonymous referee

\section{References}

Amann, F., Button, E. A., Evans, K. F., Gischig, V. S., and Blümel, M.: Experimental Study of the Brittle Behavior of Clay shale in Rapid Unconfined Compression, Rock Mech. Rock Eng., 44, 415-430, https://doi.org/10.1007/s00603-011-0156-3, 2011.

Arch, J. and Maltman, A.: Anisotropic permeability and tortuosity in deformed wet sediments, J. Geophys. Res.-Sol. Ea., 95, 90359045, https://doi.org/10.1029/JB095iB06p09035, 1990.

Bakker, E., Kaszuba, J. P., and Hangx, S. J. T.: Assessing Chemomechanical Behavior Induced by $\mathrm{CO}_{2}$-Water-rock Interactions in Clay-rich Fault Gouges, Proced. Earth Plan. Sc., 17, 292-295, https://doi.org/10.1016/j.proeps.2016.12.060, 2017.

Becker, A.: The Jura Mountains - an active foreland fold-and-thrust belt?, Tectonophysics, 321, 381-406, 2000.

Bigi, S.: An example of inversion in a brittle shear zone, J. Struct. Geol., 28, 431-443, https://doi.org/10.1016/j.jsg.2005.12.012, 2006.

Bock, H. and Blümling, P.: RA Experiment Rock mechancis analysis and synthesis: data report on rock mechanics. Mont Terri Technical Report 2000-02. Bern-Ittigen, Switzerland, available at: https://www.mont-terri.ch/content/mont-terri-internet/de/ documentation/free-reports.download/mont-terri-internet/de/ documents/technical-reports/TR2000-02s.pdf (last access: 8 January 2018), 2001.

Bock, H., Dehandschutter, B., Martin, C. D., Mazurek, M., de Haller, A., Skoczylas, F., and Davy, C.: Self-sealing of fractures in argillaceous formations in the context of geological disposal of radioactive waste: Review and Synthesis, Radioactive Waste Management, OECD 2010 NEA No. 6184, 2010.

Bonnet, E., Bour, O., Odling, N. E., Davy, P., Main, I., Cowie, P., and Berkowitz, B.: Scaling of fracture systems in geological media, Rev. Geophys., 39, 347-383, https://doi.org/10.1029/1999RG000074, 2001.

Bossart, P. J. and Thury, M.: Mont Terri Rock Laboratory: project, programme 1996 to 2007 and results, edited by: Bossart, P. and
Thury, M., Federal Office of Topography swisstopo, Wabern, Switzerland, 2008.

Bou Daher, S., Nader, F. H., Strauss, H., and Littke, R.: Depositional environment and source-rock characterisation of organic-matter rich upper santonian - upper campanian carbonates, Northern Lebanon, J. Petrol. Geol., 37, 5-24, https://doi.org/10.1111/jpg.12566, 2014.

Brodsky, E. E., Rowe, C. D., Meneghini, F., and Moore, J. C.: A geological fingerprint of low-viscosity fault fluids mobilized during an earthquake, J. Geophys. Res.-Sol. Ea., 114, 1-14, https://doi.org/10.1029/2008JB005633, 2009.

Buatier, M. D., Cavailhes, T., Charpentier, D., Lerat, J., Sizun, J. P., Labaume, P., and Gout, C.: Evidence of multi-stage faulting by clay mineral analysis: Example in a normal fault zone affecting arkosic sandstones (Annot sandstones), J. Struct. Geol., 75, 101117, https://doi.org/10.1016/j.jsg.2015.03.012, 2015.

Caine, J. S., Evans, J. P., and Forster, C. B.: Fault zone architechture and permeability structure, Geology, 24, 1025-1028, https://doi.org/10.1130/00917613(1996)024<1025:FZAAPS>2.3.CO;2, 1996.

Casciello, E., Cosgrove, J. W., Cesarano, M., Romero, E., Queralt, I., and Vergés, J.: Illite-smectite patterns in sheared Pleistocene mudstones of the Southern Apennines and their implications regarding the process of illitization: A multiscale analysis, J. Struct. Geol., 33, 1699-1711, https://doi.org/10.1016/j.jsg.2011.08.002, 2011.

Chen, X., Madden, A. S. E., and Reches, Z.: Powder Rolling as a Mechanism of Dynamic Fault Weakening, in: Fault Zone Dynamic Processes: Evolution of Fault Properties During Seismic Rupture, Geophysical Monograph, 227, 133-150, https://doi.org/10.1002/9781119156895.ch7, 2017.

Chester, F. M. and Chester, J. S.: Ultracataclasite structure and friction processes of the Punchbowl fault, San Andreas system, California, Tectonophysics, 295, 199-221, https://doi.org/10.1016/S0040-1951(98)00121-8, 1998.

Cladouhos, T. T.: A kinematic model for deformation within brittle shear zones, J. Struct. Geol., 21, 437-448, https://doi.org/10.1016/S0191-8141(98)00124-2, 1999a.

Cladouhos, T. T.: Shape preferred orientations of survivor grains in fault gouge, J. Struct. Geol., 21, 419-436, https://doi.org/10.1016/S0191-8141(98)00123-0, 1999b.

Clauer, N., Techer, I., Nussbaum, C., and Laurich, B.: Geochemical signature of paleofluids in microstructures from Main Fault in the Opalinus Clay of the Mont Terri rock laboratory, Switzerland, Swiss J. Geosci., 110, 105-128, https://doi.org/10.1007/s00015016-0253-0, 2017.

Collettini, C., Niemeijer, A., Viti, C., and Marone, C.: Fault zone fabric and fault weakness, Nature, 462, 907-910, https://doi.org/10.1038/nature08585, 2009.

Crawford, B. R., Faulkner, D. R., and Rutter, E. H.: Strength, porosity, and permeability development during hydrostatic and shear loading of synthetic quartz-clay fault gouge, J. Geophys. Res.Sol. Ea., 113, B03207, https://doi.org/10.1029/2006JB004634, 2008.

Cuss, R. J., Milodowski, A., and Harrington, J. F.: Fracture transmissivity as a function of normal and shear stress: First results in Opalinus Clay, Phys. Chem. Earth, 36, 1960-1971, https://doi.org/10.1016/j.pce.2011.07.080, 2011. 
de Haller, A., Mazurek, M., Spangenberg, J., and Möri, A.: Selfsealing of faults (SF) project?: Final report, Mont Terri Technical Report, Federal Office of Water and Geology, Bern-Ittigen, Switzerland, 2014.

Dehandschutter, B., Vandycke, S., Sintubin, M., Vandenberghe, N., and Wouters, L.: Brittle fractures and ductile shear bands in argillaceous sediments: Inferences from Oligocene Boom Clay (Belgium), J. Struct. Geol., 27, 1095-1112, https://doi.org/10.1016/j.jsg.2004.08.014, 2005.

Dellisanti, F., Pini, G. A., Tateo, F., and Baudin, F.: The role of tectonic shear strain on the illitization mechanism of mixedlayers illite-smectite. A case study from a fault zone in the Northern Apennines, Italy, Int. J. Earth Sci., 97, 601-616, https://doi.org/10.1007/s00531-007-0180-4, 2008.

Demurtas, M., Fondriest, M., Balsamo, F., Clemenzi, L., Storti, F., Bistacchi, A., and Di Toro, G.: Structure of a normal seismogenic fault zone in carbonates: The Vado di Corno Fault, Campo Imperatore, Central Apennines (Italy), J. Struct. Geol., 90, 185-206, https://doi.org/10.1016/j.jsg.2016.08.004, 2016.

Desbois, G., Urai, J. L., Hemes, S., Schröppel, B., Schwarz, J.O., Mac, M., and Weiel, D.: Multi-scale analysis of porosity in diagenetically altered reservoir sandstone from the Permian Rotliegend (Germany), J. Petrol. Sci. Eng., 140, 128-148, https://doi.org/10.1016/j.petrol.2016.01.019, 2016.

Desbois, G., Höhne, N., Urai, J. L., Bésuelle, P., and Viggiani, G.: Deformation in cemented mudrock (Callovo-Oxfordian Clay) by microcracking, granular flow and phyllosilicate plasticity: insights from triaxial deformation, broad ion beam polishing and scanning electron microscopy, Solid Earth, 8, 291-305, https://doi.org/10.5194/se-8-291-2017, 2017.

Di Toro, G., Goldsby, D. L., and Tullis, T. E.: Friction falls towards zero in quartz rock as slip velocity approaches seismic rates, Nature, 427, 436-439, https://doi.org/10.1038/nature02249, 2004.

Eseme, E., Urai, J. L., Krooss, B. M., and Littke, R.: Review of mechanical properties of oil shales: Implications for exploitation and basin modelling, Oil Shale, 24, 159-174, 2007.

Fondriest, M., Smith, S. A. F., Di Toro, G., Zampieri, D., and Mittempergher, S.: Fault zone structure and seismic slip localization in dolostones, an example from the Southern Alps, Italy, J. Struct. Geol., 45, 52-67, https://doi.org/10.1016/j.jsg.2012.06.014, 2012.

Freivogel, M. and Huggenberger, P.: Modellierung bilanzierter Profile im Gebiet Mont Terri - La Croix (Kanton Jura), in: Mont Terri Project - Geology, Paleohydrology and Stress Field of the Mont Terri Region, edited by: Heitzmann, P. and Tripet, J.-P., Federal Office for Water and Geology, Bern-Ittigen, Switzerland, 7-44, 2003.

Fu, Y. and Bryan, N. K. A.: Investigation of physical properties of quartz after focused ion beam bombardment, Appl. Phys. B, 80, 581-585, https://doi.org/10.1007/s00340-005-1746-0, 2005.

Gaucher, E. C., Fern, A. M., and Waber, H. N.: Annex 9: Rock and Mineral Characterisation of the Opalinus Clay Formation, in: Mont Terri Project: Geochemistry of Water in the Opalinus Clay Formation at the Mont Terri Rock Laboratory, edited by: Pearson, F. J., Arcos, D., Bath, A., Boisson, J., Fernandez, A. M., Gäbler, H.-E., Gaucher, E., Gautschi, A., Griffault, L., Hernán, P., and Waber, H. N., 5th ed., Federal Office for Water and Geology, Bern-Ittigen, Switzerland, p. 23, 2003.
Giger, S. B., Cox, S. F., and Tenthorey, E.: Slip localization and fault weakening as a consequence of fault gouge strengthening - Insights from laboratory experiments, Earth Planet. Sc. Lett., 276, 73-84, https://doi.org/10.1016/j.epsl.2008.09.004, 2008.

Goodwin, L. B. and Wenk, H. R.: Intrcrystalline folding and cataclasis in biotite of the Santa-Rosa mylonite: observation, TEM and HVEM, Tectonophysics, 172, 201-215, 1990.

Gratier, J. P., Renard, F., and Vial, B.: Postseismic pressure solution creep: Evidence and time-dependent change from dynamic indenting experiments, J. Geophys. Res.-Sol. Ea., 119, 2764-2779, https://doi.org/10.1002/2013JB010768, 2014.

Guo, Y. and Morgan, J. K.: Fault gouge evolution and its dependence on normal stress and rock strength - Results of discrete element simulations: Gouge zone properties, J. Geophys. Res., 112, B10403, https://doi.org/10.1029/2006JB004524, 2007.

Hadizadeh, J., Mittempergher, S., Gratier, J. P., Renard, F., Di Toro, G., Richard, J., and Babaie, H. A.: A microstructural study of fault rocks from the SAFOD: Implications for the deformation mechanisms and strength of the creeping segment of the San Andreas Fault, J. Struct. Geol., 42, 246-260, https://doi.org/10.1016/j.jsg.2012.04.011, 2012.

Haines, S. H., Van Der Pluijm, B. A., Ikari, M. J., Saffer, D. M., and Marone, C.: Clay fabric intensity in natural and artificial fault gouges: Implications for brittle fault zone processes and sedimentary basin clay fabric evolution, J. Geophys. Res.-Sol. Ea., 114, B05406, https://doi.org/10.1029/2008JB005866, 2009.

Haines, S. H., Kaproth, B., Marone, C., Saffer, D., and Van der Pluijm, B.: Shear zones in clay-rich fault gouge: A laboratory study of fabric development and evolution, J. Struct. Geol., 51, 206-225, https://doi.org/10.1016/j.jsg.2013.01.002, 2013.

Haines, S. H., Marone, C., and Saffer, D.: Frictional properties of low-angle normal fault gouges and implications for lowangle normal fault slip, Earth Planet. Sc. Lett., 408, 57-65, https://doi.org/10.1016/j.epsl.2014.09.034, 2014.

Han, R., Hirose, T., Shimamoto, T., Lee, Y., and Ando, J.-I.: Granular nanoparticles lubricate faults during seismic slip, Geology, 39, 599-602, https://doi.org/10.1130/G31842.1, 2011.

Hemes, S.: Nm-scale pore space characteristics of the Boom Clay (Mol-1 borehole) and the Ypresian clays (Kallo-1 borehole), RWTH-Aachen University, Aachen, Germany, 2015.

Hemes, S., Desbois, G., Urai, J. L., De Craen, M., and Honty, M.: Variations in the morphology of porosity in the Boom Clay Formation: insights from 2D high resolution BIB-SEM imaging and Mercury injection Porosimetry, Netherlands J. Geosci./Geol. en Mijnb., 92, 275-300, 2013.

Holland, M., Urai, J. L., van der Zee, W., Stanjek, H., and Konstanty, J.: Fault gouge evolution in highly overconsolidated claystones, J. Struct. Geol., 28, 323-332, https://doi.org/10.1016/j.jsg.2005.10.005, 2006.

Houben, M. E.: In situ characterization of the microstructure and porosity of Opalinus Clay (Mont Terri Rock Laboratory, Switzerland), RWTH-Aachen, Aachen, Germany, 2013.

Houben, M. E., Desbois, G., and Urai, J. L.: Pore morphology and distribution in the Shaly facies of Opalinus Clay (Mont Terri, Switzerland): Insights from representative 2D BIB-SEM investigations on $\mathrm{mm}$ to $\mathrm{nm}$ scale, Appl. Clay Sci., 71, 82-97, https://doi.org/10.1016/j.clay.2012.11.006, 2013.

Houben, M. E., Desbois, G., and Urai, J. L.: A comparative study of representative 2D microstructures in Shaly and Sandy fa- 
cies of Opalinus Clay (Mont Terri, Switzerland) inferred form BIB-SEM and MIP methods, Mar. Petrol. Geol., 49, 143-161, https://doi.org/10.1016/j.marpetgeo.2013.10.009, 2014.

Jaeggi, D., Laurich, B., Nussbaum, C., Schuster, K., and Connolly, P.: Tectonic structure of the "Main Fault" in the Opalinus Clay, Mont Terri rock laboratory (Switzerland), Swiss J. Geosci., 110, 67-84, https://doi.org/10.1007/s00015-016-0243-2, 2017.

Janssen, C., Wirth, R., Lin, A., and Dresen, G.: TEM microstructural analysis in a fault gouge sample of the Nojima Fault Zone, Japan, Tectonophysics, 583, 101-104, https://doi.org/10.1016/j.tecto.2012.10.020, 2013.

Jessell, M. W., Bons, P. D., Griera, A., Evans, L. A., and Wilson, C. J. L.: A tale of two viscosities, J. Struct. Geol., 31, 719-736, https://doi.org/10.1016/j.jsg.2009.04.010, 2009.

Kahle, M., Kleber, M., and Jahn, R.: Review of XRD-based quantitative analyses of clay minerals in soils: The suitability of mineral intensity factors, Geoderma, 109, 191-205, https://doi.org/10.1016/S0016-7061(02)00175-1, 2002.

Kameda, J., Okamoto, A., Sato, K., Fujimoto, K., Yamaguchi, A., and Kimura, G.: Opal-CT in chert beneath the toe of the Tohoku margin and its influence on the seismic aseismic transition in subduction zones, Geophys. Res. Lett., 44, 687-693, https://doi.org/10.1002/2016GL071784, 2017.

Kanitpanyacharoen, W., Vasin, R., Wenk, H., and Dewhurst, D. N.: Linking preferred orientations to elastic anisotropy in Muderong Shale, Australia, Geophysics, 80, C9-C19, https://doi.org/10.1190/GEO2014-0236.1, 2015.

Kendall, K.: The impossibility of comminuting small particles by compression, Nature, 272, 710-711, https://doi.org/10.1038/279169d0, 1978.

Keulen, N., Stünitz, H., and Heilbronner, R.: Healing microstructures of experimental and natural fault gouge, J. Geophys. Res., 113, B06205, https://doi.org/10.1029/2007JB005039, 2008.

Kirkpatrick, J. D., Rowe, C. D., White, J. C., and Brodsky, E. E.: Silica gel formation during fault slip: Evidence from the rock record, Geology, 41, 1015-1018, https://doi.org/10.1130/G34483.1, 2013.

Klaver, J. M.: Pore space characterization of organic-rich shales using BIB-SEM, RWTH-Aachen, Aachen, Germany, 2015.

Klaver, J. M., Desbois, G., Urai, J. L., and Littke, R.: BIB-SEM study of the pore space morphology in early mature Posidonia Shale from the Hils area, Germany, Int. J. Coal Geol., 103, 1225, https://doi.org/10.1016/j.coal.2012.06.012, 2012.

Laurich, B.: Evolution of microstructure and porosity in faulted Opalinus Clay, RWTH-Aachen University, Aachen, Germany, 2015.

Laurich, B., Urai, J. L., Desbois, G., Vollmer, C., and Nussbaum, C.: Microstructural evolution of an incipient fault zone in Opalinus Clay: Insights from an optical and electron microscopic study of ion-beam polished samples from the Main Fault in the Mt-Terri underground research laboratory, J. Struct. Geol., 67, 107-128, https://doi.org/10.1016/j.jsg.2014.07.014, 2014.

Laurich, B., Urai, J. L., and Nussbaum, C.: Microstructures and deformation mechanisms in Opalinus Clay: insights from scaly clay from the Main Fault in the Mont Terri Rock Laboratory (CH), Solid Earth, 8, 27-44, https://doi.org/10.5194/se-8-272017, 2017.

Lerouge, C., Grangeon, S., Claret, F., Gaucher, E., Blanc, P., Guerrot, C., Flehoc, C., Wille, G., and Mazurek, M.: Mineralogical and Isotopic record of diagenesis from the Opalinus Clay formation at Benken, Switzerland: Implications for the modeling of pore-water chemistry in a clay formation, Clay. Clay Miner., 62, 286-312, https://doi.org/10.1346/CCMN.2014.0620404, 2014.

Lin, A.: S-C fabrics developed in cataclastic rocks from the Nojima fault zone, Japan and their implications for tectonic history, J. Struct. Geol., 23, 1167-1178, https://doi.org/10.1016/S01918141(00)00171-1, 2001.

Littke, R., Urai, J. L., Uffmann, A. K., and Risvanis, F.: Reflectance of dispersed vitrinite in Palaeozoic rocks with and without cleavage: Implications for burial and thermal history modeling in the Devonian of Rursee area, northern Rhenish Massif, Germany, Int. J. Coal Geol., 89, 41-50, https://doi.org/10.1016/j.coal.2011.07.006, 2012.

Logan, J. M., Friedman, M., Higgs, N., Dengo, C., and Shimamoto, T.: Experimental studies of simulated gouge and their application to studies of natural fault zones, in: Proceedings of Conference VIII on Analysis of Actual Fault Zones in Bedrock, 1-5 April 1979, US Geological Survey, Open File Report, Menlo Park, California, USA, 79-1239, 1979.

Logan, J. M., Dengo, C. A., Higgs, N. G., and Wang, Z. Z.: Chapter 2 Fabrics of Experimental Fault Zones: Their Development and Relationship to Mechanical Behavior, in: Fault Mechanics and Transport Properties of Rocks - A Festschrift in Honor of W. F. Brace, edited by: Evans, B. and Wong, T., Academic Press, 51, 33-67, https://doi.org/10.1016/S0074-6142(08)628144, 1992.

Mair, K. and Abe, S.: Breaking Up: Comminution Mechanisms in Sheared Simulated Fault Gouge, Pure Appl. Geophys., 168, 2277-2288, https://doi.org/10.1007/s00024-011-0266-6, 2011.

Mazurek, M. and De Haller, A.: Pore-water evolution and solutetransport mechanisms in Opalinus Clay at Mont Terri and Mont Russelin (Canton Jura, Switzerland), Swiss J. Geosci., 110, 129149, https://doi.org/10.1007/s00015-016-0249-9, 2017.

Mazurek, M., Hurford, A. J., and Leu, W.: Unravelling the multi-stage burial history of the Swiss Molasse Basin: integration of apatite fission track, vitrinite reflectance and biomarker isomerisation analysis, Basin Res., 18, 27-50, https://doi.org/10.1111/j.1365-2117.2006.00286.x, 2006.

Mazurek, M., Alt-Epping, P., Bath, A., Gimmi, T., Niklaus Waber, H., Buschaert, S., De Cannière, P., De Craen, M., Gautschi, A., Savoye, S., Vinsot, A., Wemaere, I., and Wouters, L. : Natural tracer profiles across argillaceous formations, Appl. Geochem., 26, 1035-1064, https://doi.org/10.1016/j.apgeochem.2011.03.124, 2011.

Milliken, K. L. and Reed, R. M.: Multiple causes of diagenetic fabric anisotropy in weakly consolidated mud, Nankai accretionary prism, IODP Expedition 316, J. Struct. Geol., 32, 1887-1898, https://doi.org/10.1016/j.jsg.2010.03.008, 2010.

Mizoguchi, K., Hirose, T., Shimamoto, T., and Fukuyama, E.: High-velocity frictional behavior and microstructure evolution of fault gouge obtained from Nojima fault, southwest Japan, Tectonophysics, 471, 285-296, https://doi.org/10.1016/j.tecto.2009.02.033, 2009.

Morgenstern, N. R. and Tchalenko, J. S.: Microstructural observations on shear zones from slips in natural clays, in: Proceedings of the Geotechnical Conference 1967, Oslo , Norway, 147-152, 1967. 
Nagra: Technischer Bericht 02-03, Projekt Opalinuston, Synthese der geowissenschaftlichen Untersuchungsergebnisse, Wettingen, Switzerland, 2002.

Nussbaum, C. and Bossart, P.: Geology, in: Mont Terri Rock Laboratory. Project, Programme 1996 to 2007 and Results, edited by: Thury, M. and Bossart, P., Swiss Geological Survey, Wabern, Switzerland, 29-39, 2008.

Nussbaum, C., Bossart, P., Amann, F., and Aubourg, C.: Analysis of tectonic structures and excavation induced fractures in the Opalinus Clay, Mont Terri underground rock laboratory (Switzerland), Swiss J. Geosci., 104, 187-210, https://doi.org/10.1007/s00015011-0070-4, 2011.

Nussbaum, C., Kloppenburg, A., Caer, T., and Bossart, P.: Tectonic evolution around the Mont Terri rock laboratory, northwestern Swiss Jura: constraints from kinematic forward modelling, Swiss J. Geosci., 110, 39-66, https://doi.org/10.1007/s00015016-0248-x, 2017.

Orellana, L. F., Violay, M., Gramajo, E., Henry, P., Amann, F., and Nusbaumm, C.: Petro-physical characterization of the Main Fault at the Mont Terri Laboratory, in: 14th Swiss Geoscience Meeting, 18-19 November 2016, Geneva, Switzerland, P 8.12, 2016.

Passchier, C. W. and Trouw, R. A. J.: Microtectonics, 2nd editio., Springer-Verlag, Berlin/Heidelberg, Germany, 2005.

Pearson, F. J., Arcos, D., Bath, A., Boisson, J., Fernandez, A. M., Gäbler, H., Gaucher, E., Gautschi, A., and Griffault, L.: Mont Terri Project: Geochemistry of Water in the Opalinus Clay Formation at the Mont Terri Rock Laboratory, 5th ed., edited by: Pearson, F. J., Arcos, D., Bath, A., Boisson, J., Fernandez, A. M., Gäbler, H.-E., Gaucher, E., Gautschi, A.., Griffault, L., Hernán, P., and Waber, H. N., Federal Office for Water and Geology, Bern-Ittigen, Switzerland, 2003.

Power, W. L. and Tullis, T. E.: The relationship between slickenside surfaces in fine-grained quartz and the seismic cycle, J. Struct. Geol., 11, 879-893, 1989.

Rowe, C. D., Fagereng, Å., Miller, J. A., and Mapani, B.: Signature of coseismic decarbonation in dolomitic fault rocks of the Naukluft Thrust, Namibia, Earth Planet. Sc. Lett., 333-334, 200-210, https://doi.org/10.1016/j.epsl.2012.04.030, 2012.

Rutter, E. H. and Elliott, D.: The Kinetics of Rock Deformation by Pressure Solution (and Discussion), Philos. T. Roy. Soc. A, 283, 203-219, https://doi.org/10.1098/rsta.1976.0079, 1976.

Sammis, C. G. and King, G. C. P.: Mechanical origin of power law scaling in fault zone rock, Geophys. Res. Lett., 34, 2-5, https://doi.org/10.1029/2006GL028548, 2007.

Sasseville, C., Tremblay, A., Clauer, N., and Liewig, N.: K-Ar age constraints on the evolution of polydeformed fold-thrust belts: the case of the Northern Appalachians (southern Quebec), J. Geodyn., 45, 99-119, https://doi.org/10.1016/j.jog.2007.07.004, 2008.

Schleicher, A. M., van der Pluijm, B. A., and Warr, L. N.: Nanocoatings of clay and creep of the San Andreas fault at Parkfield, California, Geology, 38, 667-670, https://doi.org/10.1130/G31091.1, 2010.

Sibson, R. H.: Fault rocks and fault mechanisms, J. Geol. Soc. London, 133, 191-213, 1977.
Sigal, R. F.: A methodology for blank and conformance corrections for high pressure mercury porosimetry, Meas. Sci. Technol., 20, 045108, https://doi.org/10.1088/0957-0233/20/4/045108, 2009.

Solum, J. G.: Influence of phyllosilicate mineral assemblages, fabrics, and fluids on the behavior of the Punchbowl fault, southern California, J. Geophys. Res., 108, 1-12, https://doi.org/10.1029/2002JB001858, 2003.

Takizawa, S. and Ogawa, Y.: Dilatant clayey microstructure in the Barbados décollement zone, J. Struct. Geol., 21, 117-122, 1999.

Ufer, K., Stanjek, H., Roth, G., Dohrmann, R., Kleeberg, R., and Kaufhold, S.: Quantitative phase analysis of bentonites by the rietveld method, Clay. Clay Miner., 56, 272-282, https://doi.org/10.1346/CCMN.2008.0560210, 2008.

Urai, J. L. and Wong, S. W.: Deformation mechanisms in experimentally deformed shales, Euro. Geophys. Soc. Annales Geophysicae , 12, C98, 1994.

Vannucchi, P., Maltman, A., Bettelli, G., and Clennell, B.: On the nature of scaly fabric and scaly clay, J. Struct. Geol., 25, 673688, https://doi.org/10.1016/S0191-8141(02)00066-4, 2003.

Viti, C.: Exploring fault rocks at the nanoscale, J. Struct. Geol., 33, 1715-1727, https://doi.org/10.1016/j.jsg.2011.10.005, 2011.

Vrolijk, P. J. and van der Pluijm, B. A.: Clay gouge, J. Struct. Geol., 21, 1039-1048, https://doi.org/10.1016/S0191-8141(99)00103$0,1999$.

Vrolijk, P. J., Urai, J. L., and Kettermann, M.: Clay smear: Review of mechanisms and applications, J. Struct. Geol., 86, 95-152, https://doi.org/10.1016/j.jsg.2015.09.006, 2016.

Warr, L. N. and Cox, S.: Clay mineral transformations and weakening mechanisms along the Alpine Fault, New Zealand, Geol. Soc. London, Spec. Publ., 186, 85-101, https://doi.org/10.1144/GSL.SP.2001.186.01.06, 2001.

Warr, L. N., Wojatschke, J., Carpenter, B. M., Marone, C., Schleicher, A. M., and van der Pluijm, B. A.: A "slice-and-view" (FIBSEM) study of clay gouge from the SAFOD creeping section of the San Andreas Fault at $\sim 2.7 \mathrm{~km}$ depth, J. Struct. Geol., 69, 234-244, https://doi.org/10.1016/j.jsg.2014.10.006, 2014.

Wenk, H.-R., Voltolini, M., Kern, H., Popp, T., and Mazurek, M.: Anisotropy in shale from Mont Terri, Lead. Edge, 27, 742-748, https://doi.org/10.1190/1.2944159, 2008.

Yan, Y.: Deformation microfabrics of clay gouge, Lewis Thrust, Canada: a case for fault weakening from clay transformation, Geol. Soc. London, Spec. Publ., 186, 103-112, https://doi.org/10.1144/GSL.SP.2001.186.01.07, 2001.

Zhang, G., Wei, Z., Ferrell, R. E., Guggenheim, S., Cygan, R. T., and Luo, J.: Evaluation of the elasticity normal to the basal plane of non-expandable 2:1 phyllosilicate minerals by nanoindentation, Am. Mineral., 95, 863-869, https://doi.org/10.2138/am.2010.3398, 2010.

Zhang, S., Tullis, T. E., and Scruggs, V. J.: Implications of permeability and its anisotropy in a mica gouge for pore pressures in fault zones, Tectonophysics, 335, 37-50, https://doi.org/10.1016/S0040-1951(01)00044-0, 2001. 